\title{
Global scale variability of the mineral dust long-wave refractive index: a new dataset of in situ measurements for climate modeling and remote sensing
}

\author{
Claudia Di Biagio ${ }^{1}$, Paola Formenti ${ }^{1}$, Yves Balkanski ${ }^{2}$, Lorenzo Caponi ${ }^{1,3}$, Mathieu Cazaunau ${ }^{1}$, Edouard Pangui ${ }^{1}$, \\ Emilie Journet $^{1}$, Sophie Nowak ${ }^{4}$, Sandrine Caquineau ${ }^{5}$, Meinrat O. Andreae ${ }^{6,12}$, Konrad Kandler ${ }^{7}$, Thuraya Saeed ${ }^{8}$, \\ Stuart Piketh $^{9}$, David Seibert ${ }^{10}$, Earle Williams ${ }^{11}$, and Jean-François Doussin ${ }^{1}$ \\ ${ }^{1}$ Laboratoire Interuniversitaire des Systèmes Atmosphériques (LISA), UMR7583, CNRS, Université Paris Est Créteil \\ et Université Paris Diderot, Institut Pierre et Simon Laplace, Créteil, France \\ ${ }^{2}$ Laboratoire des Sciences du Climat et de l'Environnement, CEA CNRS UVSQ, 91191, Gif sur Yvette, France \\ ${ }^{3}$ Department of Physics \& INFN, University of Genoa, Genoa, Italy \\ ${ }^{4}$ Plateforme RX UFR de chimie, Université Paris Diderot, Paris, France \\ ${ }^{5}$ IRD-Sorbonne Universités (UPMC, Univ. Paris 06), CNRS-MNHN, LOCEAN Laboratory, IRD France-Nord, \\ 93143 Bondy, France \\ ${ }^{6}$ Biogeochemistry Department, Max Planck Institute for Chemistry, P.O. box 3060, 55020, Mainz, Germany \\ ${ }^{7}$ Institut für Angewandte Geowissenschaften, Technische Universität Darmstadt, Schnittspahnstr. 9, \\ 64287 Darmstadt, Germany \\ ${ }^{8}$ Science department, College of Basic Education, Public Authority for Applied Education and Training, Al-Ardeya, Kuwait \\ ${ }^{9}$ Climatology Research Group, Unit for Environmental Science and Management, North-West University, \\ Potchefstroom, South Africa \\ ${ }^{10}$ Walden University, Minneapolis, Minnesota, USA \\ ${ }^{11}$ Parsons Laboratory, Massachusetts Institute of Technology, Cambridge, Massachusetts, USA \\ ${ }^{12}$ Geology and Geophysics Department, King Saud University, Riyadh, Saudi Arabia
}

Correspondence to: Claudia Di Biagio (cldibiagio@gmail.com) and Paola Formenti (paola.formenti@lisa.u-pec.fr)

Received: 12 July 2016 - Discussion started: 19 October 2016

Revised: 11 January 2017 - Accepted: 14 January 2017 - Published: 9 February 2017

\begin{abstract}
Modeling the interaction of dust with long-wave (LW) radiation is still a challenge because of the scarcity of information on the complex refractive index of dust from different source regions. In particular, little is known about the variability of the refractive index as a function of the dust mineralogical composition, which depends on the specific emission source, and its size distribution, which is modified during transport. As a consequence, to date, climate models and remote sensing retrievals generally use a spatially invariant and time-constant value for the dust LW refractive index.

In this paper, the variability of the mineral dust LW refractive index as a function of its mineralogical composition and size distribution is explored by in situ measurements in a large smog chamber. Mineral dust aerosols were gener-
\end{abstract}

ated from 19 natural soils from 8 regions: northern Africa, the Sahel, eastern Africa and the Middle East, eastern Asia, North and South America, southern Africa, and Australia. Soil samples were selected from a total of 137 available samples in order to represent the diversity of sources from arid and semi-arid areas worldwide and to account for the heterogeneity of the soil composition at the global scale. Aerosol samples generated from soils were re-suspended in the chamber, where their LW extinction spectra (3-15 $\mu \mathrm{m})$, size distribution, and mineralogical composition were measured. The generated aerosol exhibits a realistic size distribution and mineralogy, including both the sub- and super-micron fractions, and represents in typical atmospheric proportions the main LW-active minerals, such as clays, quartz, and calcite. 
The complex refractive index of the aerosol is obtained by an optical inversion based upon the measured extinction spectrum and size distribution.

Results from the present study show that the imaginary LW refractive index $(k)$ of dust varies greatly both in magnitude and spectral shape from sample to sample, reflecting the differences in particle composition. In the $3-15 \mu \mathrm{m}$ spectral range, $k$ is between $\sim 0.001$ and 0.92 . The strength of the dust absorption at $\sim 7$ and $11.4 \mu \mathrm{m}$ depends on the amount of calcite within the samples, while the absorption between 8 and $14 \mu \mathrm{m}$ is determined by the relative abundance of quartz and clays. The imaginary part $(k)$ is observed to vary both from region to region and for varying sources within the same region. Conversely, for the real part $(n)$, which is in the range 0.84-1.94, values are observed to agree for all dust samples across most of the spectrum within the error bars. This implies that while a constant $n$ can be probably assumed for dust from different sources, a varying $k$ should be used both at the global and the regional scale. A linear relationship between the magnitude of the imaginary refractive index at 7.0, 9.2, and $11.4 \mu \mathrm{m}$ and the mass concentration of calcite and quartz absorbing at these wavelengths was found. We suggest that this may lead to predictive rules to estimate the LW refractive index of dust in specific bands based on an assumed or predicted mineralogical composition, or conversely, to estimate the dust composition from measurements of the LW extinction at specific wavebands.

Based on the results of the present study, we recommend that climate models and remote sensing instruments operating at infrared wavelengths, such as IASI (infrared atmospheric sounder interferometer), use regionally dependent refractive indices rather than generic values. Our observations also suggest that the refractive index of dust in the LW does not change as a result of the loss of coarse particles by gravitational settling, so that constant values of $n$ and $k$ could be assumed close to sources and following transport.

The whole dataset of the dust complex refractive indices presented in this paper is made available to the scientific community in the Supplement.

\section{Introduction}

Mineral dust is one of the most abundant aerosol species in the atmosphere and contributes significantly to radiative perturbation, at both the regional and the global scale (Miller et al., 2014). The direct radiative effect of mineral dust acts at both short-wave (SW) and long-wave (LW) wavelengths (Tegen and Lacis, 1996). This is due to the very large size spectrum of these particles, which extends from hundreds of nanometers to tenths of micrometers, and to their mineralogy, which includes minerals with absorption bands at both SW and LW wavelengths (Sokolik et al., 1998; Sokolik and Toon, 1999). The sub-micron dust fraction controls the in- teraction in the SW, where scattering is the dominant process, while the super-micron size fraction drives the LW interaction, dominated by absorption (Sokolik and Toon, 1996, 1999). The SW and LW terms have opposite effects at the surface, the top of the atmosphere (TOA), and within the aerosol layer (Hsu et al., 2000; Slingo et al., 2006). The dust SW effect is to cool the surface and at the TOA, and to warm the dust layer; conversely, the dust LW effect induces a warming of the surface and TOA, and the cooling of the atmospheric dust layer. The net effect of dust at the TOA is generally a warming over bright surfaces (e.g., deserts; Yang et al., 2009) and a cooling over dark surfaces (e.g., oceans; di Sarra et al., 2011).

The interaction of dust with LW radiation has important implications for climate modeling and remote sensing. Many studies have shown the key role of the LW effect in modulating the SW perturbation of dust not only close to sources (Slingo et al., 2006), where the coarse size fraction is dominant (Schütz and Jaenicke, 1974; Ryder et al., 2013a), but also after medium- and long-range transport (di Sarra et al., 2011; Meloni et al., 2015), when the larger particles $(>10 \mu \mathrm{m})$ were preferentially removed by wet and dry deposition (Schütz et al., 1981; Maring et al., 2003; Osada et al., 2014). Thus, the dust LW term has importance over the entire dust life cycle, and has to be taken into account in order to evaluate the radiative effect of dust particles on the climate system. Second, the signature of the dust LW absorption modifies the TOA radiance spectrum, which influences the retrieval of several climate parameters by satellite remote sensing. Misinterpretations of the data may occur if the signal of dust is not accurately taken into account within satellite inversion algorithms (Sokolik, 2002; DeSouza-Machado et al., 2006; Maddy et al., 2012). In addition, the dust LW signature obtained by spaceborne satellite data in the $8-12 \mu \mathrm{m}$ window region is used to estimate the concentration fields and optical depth of dust (Klüser et al., 2011; Clarisse et al., 2013; Vandenbussche et al., 2013; Capelle et al., 2014; Cuesta et al., 2015), with potential important applications for climate and air quality studies, health issues, and visibility.

Currently, the magnitude and the spectral fingerprints of the dust signal in the LW are still very uncertain. One of the factors contributing the highest uncertainty is the poor knowledge regarding the dust spectral complex refractive in$\operatorname{dex}(m=n-i k$; Claquin et al., 1998; Liao and Seinfeld, 1998; Sokolik et al., 1998; Highwood et al., 2003; Colarco et al., 2014). The dust complex refractive index in the LW depends on the particle mineralogical composition, in particular the relative proportion of quartz, clays (kaolinite, illite, smectite, chlorite), and calcium-rich minerals (calcite, dolomite), each exhibiting specific absorption features in the LW spectrum (Sokolik et al., 1993, 1998). Because of the variability of the dust composition resulting from the variability of composition of the source soils (Jeong, 2008; Scheuvens et al., 2013; Formenti et al., 2014; Journet et al., 2014), atmospheric dust produced from different regions of 
Table 1. Measured and retrieved quantities and their estimated uncertainties. For further details refer to Sect. 2.

\begin{tabular}{|c|c|c|c|}
\hline \multicolumn{2}{|r|}{ Parameter } & \multirow{2}{*}{$\begin{array}{l}\text { Uncertainty } \\
<10 \%\end{array}$} & \multirow{2}{*}{$\begin{array}{l}\text { Uncertainty calculation } \\
\text { Quadratic combination of noise } \\
(\sim 1 \%) \text { and standard deviation over } \\
10 \min (5-10 \%)\end{array}$} \\
\hline $\begin{array}{l}\text { Optical } \\
\text { LW }\end{array}$ & Transmission $3-15 \mu \mathrm{m}, T$ & & \\
\hline & Extinction coefficient $3-15 \mu \mathrm{m}, \beta_{\mathrm{ext}}(\lambda)=\frac{-\ln (T(\lambda))}{x}$ & $\sim 10 \%$ & $\begin{array}{l}\text { Error propagation formula* consid- } \\
\text { ering uncertainties on the measured } \\
\text { transmission } T \text { and the optical path } \\
x(\sim 2 \%)\end{array}$ \\
\hline \multirow[t]{5}{*}{$\begin{array}{l}\text { Size dis- } \\
\text { tribution }\end{array}$} & SMPS geometrical diameter $\left(D_{\mathrm{g}}\right)$ & $\sim 6 \%$ & $\begin{array}{l}\text { Error propagation formula* consid- } \\
\text { ering the uncertainty on the esti- } \\
\text { mated shape factor } \chi(\sim 6 \%)\end{array}$ \\
\hline & SkyGrimm geometrical diameter $\left(D_{\mathrm{g}}\right)$ & $<15.2 \%$ & $\begin{array}{l}\text { Standard deviation of the } D_{\mathrm{g}} \text { values } \\
\text { obtained for different refractive in- } \\
\text { dex values used in the optical to ge- } \\
\text { ometrical conversion }\end{array}$ \\
\hline & WELAS geometrical diameter $\left(D_{\mathrm{g}}\right)$ & $\sim 5-7 \%$ & The same as for the SkyGrimm \\
\hline & {$\left[\mathrm{d} N / \mathrm{d} \log D_{\mathrm{g}}\right]_{\text {Corr,WELAS }}=\left[\mathrm{d} N / \mathrm{d} \log D_{\mathrm{g}}\right] /\left[1-L_{\text {WELAS }}\left(D_{\mathrm{g}}\right)\right]$} & $\begin{array}{l}\sim 20- \\
70 \%\end{array}$ & $\begin{array}{l}\text { Error propagation formula* con- } \\
\text { sidering the } \mathrm{d} N / \mathrm{d} \log D_{\mathrm{g}} \mathrm{SD} \text { over } \\
10 \mathrm{~min} \text { and the uncertainty on } \\
L_{\text {WELAS }}(\sim 50 \% \text { at } 2 \mu \mathrm{m}, \sim 10 \% \\
\text { at } 8 \mu \mathrm{m})\end{array}$ \\
\hline & {$\left[\mathrm{d} N / \mathrm{d} \log D_{\mathrm{g}}\right]_{\text {filter }}=\left[\mathrm{d} N / \mathrm{d} \log D_{\mathrm{g}}\right]_{\text {CESAM }} \times\left[1-L_{\text {filter }}\left(D_{\mathrm{g}}\right)\right]$} & $\begin{array}{l}\sim 25- \\
70 \%\end{array}$ & $\begin{array}{l}\text { Error propagation formula* consid- } \\
\text { ering the uncertainties on } \\
\left(\mathrm{d} N / \mathrm{d} \log D_{\mathrm{g}}\right) \mathrm{CESAM} \text { and } L_{\mathrm{filter}} \\
(\sim 55 \% \text { at } 2 \mu \mathrm{m}, \sim 10 \% \text { at } 12 \mu \mathrm{m})\end{array}$ \\
\hline \multirow[t]{6}{*}{$\begin{array}{l}\text { Mineral- } \\
\text { ogical } \\
\text { composi- } \\
\text { tion }\end{array}$} & Clay mass $\left.\left(m_{\text {Clay }}=M_{\text {total }}-m_{\mathrm{Q}}-m_{\mathrm{F}}-m_{\mathrm{C}}-m_{\mathrm{D}}-m_{\mathrm{G}}\right)\right)$ & $8-26 \%$ & $\begin{array}{l}\text { Error propagation formula* consid- } \\
\text { ering the uncertainty on } M_{\text {total }}(4- \\
18 \%) \text { and that on } m_{\mathrm{Q}}, m_{\mathrm{F}}, m_{\mathrm{C}}, m_{\mathrm{D}} \text {, } \\
\text { and } m_{\mathrm{G}}\end{array}$ \\
\hline & Quartz mass $\left(m_{\mathrm{Q}}=S_{\mathrm{Q}} / K_{\mathrm{Q}}\right)$ & $9 \%$ & $\begin{array}{l}\text { Error propagation formula* consid- } \\
\text { ering the uncertainty on the DRX } \\
\text { surface area } S_{\mathrm{Q}}(\sim 2 \%) \text { and } K_{\mathrm{Q}} \\
(9.4 \%)\end{array}$ \\
\hline & Feldspars mass $\left(m_{\mathrm{F}}=S_{\mathrm{F}} / K_{\mathrm{F}}\right)$ & $\begin{array}{l}14 \% \text { (or- } \\
\text { those), } 8 \% \\
\text { (albite) }\end{array}$ & $\begin{array}{l}\text { The same as for the quartz, } K_{\mathrm{F}} \text { un- } \\
\text { certainty } 13.6 \% \text { (orthose) and } 8.4 \% \\
\text { (albite) }\end{array}$ \\
\hline & Calcite mass $\left(m_{\mathrm{C}}=S_{\mathrm{C}} / K_{\mathrm{C}}\right)$ & $11 \%$ & $\begin{array}{l}\text { The same as for the quartz, } K_{\mathrm{C}} \text { un- } \\
\text { certainty } 10.6 \%\end{array}$ \\
\hline & Dolomite mass $\left(m_{\mathrm{D}}=S_{\mathrm{D}} / K_{\mathrm{D}}\right)$ & $10 \%$ & $\begin{array}{l}\text { The same as for the quartz, } K_{\mathrm{D}} \text { un- } \\
\text { certainty } 9.4 \%\end{array}$ \\
\hline & Gypsum mass $\left(m_{\mathrm{G}}=S_{\mathrm{G}} / K_{\mathrm{G}}\right)$ & $18 \%$ & $\begin{array}{l}\text { The same as for the quartz, } K_{\mathrm{G}} \text { un- } \\
\text { certainty } 17.9 \%\end{array}$ \\
\hline
\end{tabular}

$* \sigma_{f}=\sqrt{\sum_{i=1}^{n}\left(\frac{\partial f}{\partial x_{i}} \sigma_{x_{i}}\right)^{2}}$

the world is expected to have a varying complex refractive index. Additional variability is expected to be introduced during transport due to the progressive loss of coarse particles by gravitational settling and chemical processing (particle mixing, heterogeneous reactions, water uptake), which both change the composition of the particles (Pye et al., 1987; Usher et al., 2003). As a consequence, the refractive index of dust is expected to vary widely at the regional and global scale.

Several studies have recommended taking into account the variability of the dust $\mathrm{LW}$ refractive index in order to correctly represent its effect in climate models and satellite retrieval algorithms (Sokolik et al., 1998; Claquin et al., 1999; Balkanski et al., 2007; Colarco et al., 2014; Capelle et al., 2014; among others). However, to date this is precluded by 
the limited body of observations available. Most past studies on the LW refractive index have been performed on single synthetic minerals (see Table 1 in Otto et al., 2009). These data, however, are not adequate to represent atmospheric dust because of the chemical differences between the reference minerals and the minerals in the natural aerosol, and also because of the difficulty of effectively evaluating the refractive index of the dust aerosol based only on information on its single constituents (e.g., McConnell et al., 2010). On the other hand, very few studies have been performed on natural aerosol samples. They include the estimates obtained with the KBr pellet technique by Volz (1972, 1973), Fouquart (1987), and, more recently, by Di Biagio et al. (2014a), on dust samples collected at a few geographical locations (Germany, Barbados, Niger, and Algeria). Besides hardly representing global dust sources, these datasets are also difficult to extrapolate to atmospheric conditions as (i) they mostly refer to unknown dust mineralogical composition and size distribution, and also (ii) are obtained from analyses of field samples that might have experienced unknown physico-chemical transformations. In addition, they have a rather coarse spectral resolution, which is sometimes insufficient to resolve the main dust spectral features.

As a consequence, climate models and satellite retrievals presently use a spatially invariant and time-constant value for the dust LW refractive index (e.g., Miller et al., 2014; Capelle et al., 2014), implicitly assuming a uniform as well as transport- and processing-invariant dust composition.

Recently, novel data of the LW refractive index for dust from the Sahara, the Sahel, and the Gobi deserts have been obtained from in situ measurements in a large smog chamber (Di Biagio et al., 2014b; hereinafter DB14). These measurements were performed in the realistic and dynamic environment of the $4.2 \mathrm{~m}^{3}$ CESAM (Chambre Expérimentale de Simulation Atmosphérique Multiphasique, which translates as "multiphase atmospheric experimental simulation chamber"; Wang et al., 2011), using a validated generation mechanism to produce mineral dust from parent soils (Alfaro et al., 2004). The mineralogical composition and size distribution of the particles were measured along with the optical data, thus providing a link between particle physico-chemical and optical properties.

In this study, we review, optimize, and extend the approach of DB14 to investigate the LW optical properties of mineral dust aerosols from 19 soils from major source regions worldwide, in order to (i) characterize the dependence of the dust LW refractive index on the particle origin and different mineralogical compositions, and (ii) investigate the variability of the refractive index as a function of the change in size distribution that may occur during medium- and long-range transport.

The paper is organized as follows: in Sect. 2 we describe the experimental set-up, instrumentation and data analysis, while in Sect. 3 the algorithm to retrieve the LW complex refractive index from observations is discussed. Criteria for soil selection and their representativeness of the global dust are discussed in Sect. 4. Results are presented in Sect. 5. At first, the atmospheric representativeness in terms of mineralogy and size distribution of the generated aerosols used in the experiments is evaluated (Sect. 5.1 and 5.2), then the extinction and complex refractive index spectra obtained for the different source regions and at different aging times in the chamber are presented in Sect. 5.3. The discussion of the results, a comparison with the literature, and the main conclusions are given in Sects. 6 and 7.

\section{Experimental set-up and instrumentation}

The schematic configuration of the CESAM set-up for the dust experiments is shown in Fig. 1. Prior to each experiment, the chamber was evacuated and kept at a pressure of $3 \times 10^{-4} \mathrm{hPa}$. Then, the reactor was filled with a mixture of $80 \% \mathrm{~N}_{2}$ (produced by evaporation from a pressurized liquid nitrogen tank, Messer, purity $>99.995 \%$ ) and $20 \% \mathrm{O}_{2}$ (Linde, 5.0). The chamber was equipped with a four-blade stainless steel fan to achieve homogeneous conditions within the chamber volume (with a typical mixing time of approximately $1 \mathrm{~min}$ ). Mineral dust aerosols generated from parent soils were dispersed into the chamber and left in suspension for a time period of 60-120 min, whilst monitoring of the evolution of their physico-chemical and optical properties took place. The LW spectrum of the dust aerosols was measured by means of an in situ Fourier transform infrared (FTIR) spectrometer. Concurrently, the particle size distribution and the SW scattering, absorption, and extinction coefficients were measured by several instruments sampling aerosols from the chamber. They include a scanning mobility particle sizer (SMPS) and WELAS and SkyGrimm optical particle counters for the size distribution, a nephelometer (TSI Inc. model 3563), an aethalometer (Magee Sci. model AE31), and two cavity-attenuated phase shift extinction analyzers (CAPS PMeX by Aerodyne) for aerosol SW optical properties. Dust samples were also collected on polycarbonate filters over the largest part of each experiment $(47 \mathrm{~mm}$ Nuclepore, Whatman, nominal pore size $0.4 \mu \mathrm{m}$ ) for an analysis of the particle mineralogical composition averaged over the length of the experiment.

The inlets for sampling aerosols from the chamber (for size and SW optics measurements and filter sampling) consisted of two parts: (1) a stainless steel tube $(\sim 20-40 \mathrm{~cm}$ length, $9.5 \mathrm{~mm}$ diameter) located inside CESAM, which extracted air from the interior of the chamber, and (2) an external connection from the chamber to the instruments. All external connections were made using $0.64 \mathrm{~cm}$ conductive silicone tubing (TSI Inc.) to minimize particle loss by electrostatic deposition. The sampling lines were designed to be as straight and as short as possible, and their total length varied between 40 and $120 \mathrm{~cm}$. The possible losses as a function of particle diameter were carefully estimated for each inlet 


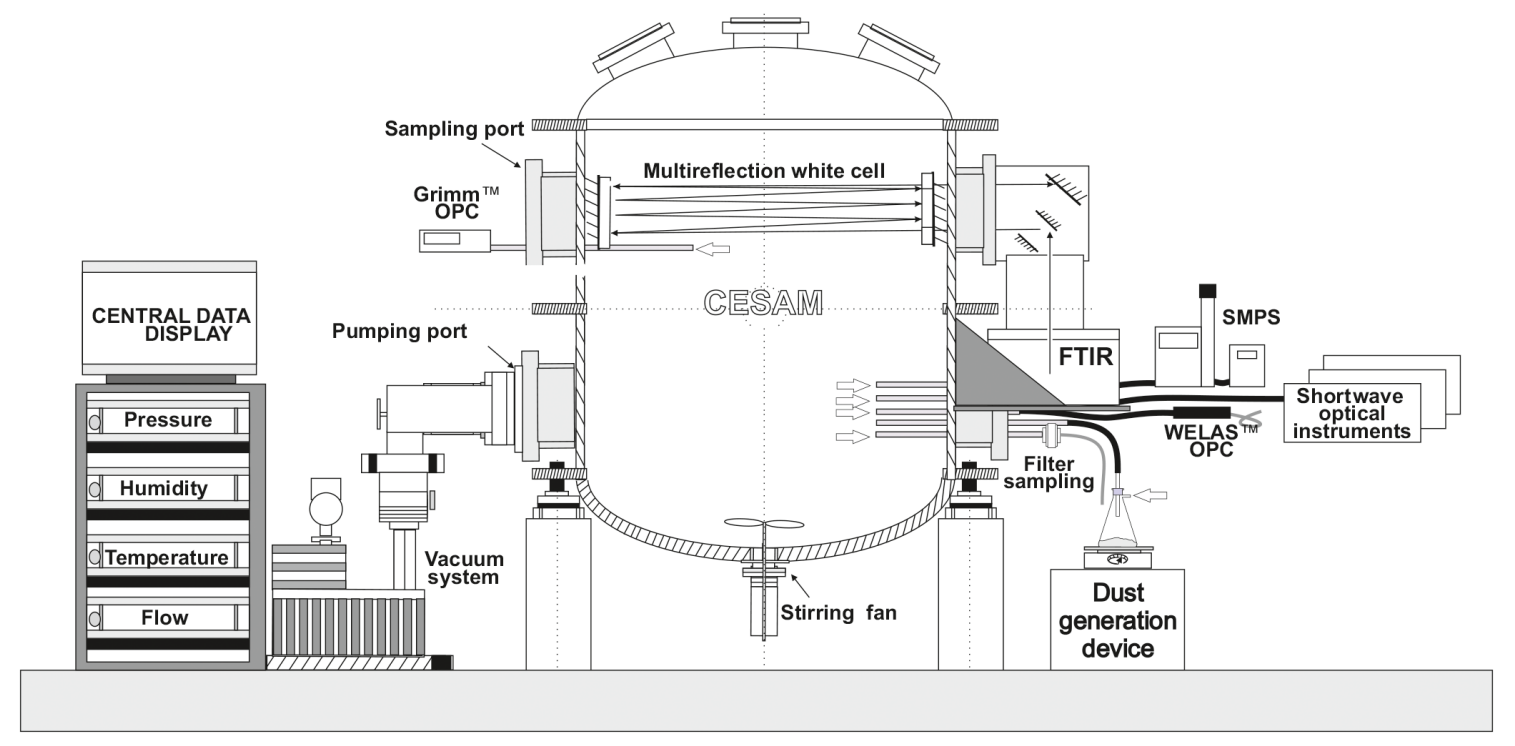

Figure 1. Schematic configuration of the CESAM set up for the dust experiments. The dust generation (vibrating plate, Büchner flask containing the soil sample) and injection system is shown at the bottom on the right side. The position of the SMPS, WELAS, and SkyGrimm used for measuring the size distribution, FTIR spectrometer, SW optical instruments, and filter sampling system are also indicated.

and the related data properly corrected (Sect. 2.3.2). To compensate for the air being extracted from the chamber by the various instruments, a particle-free $\mathrm{N}_{2}-\mathrm{O}_{2}$ mixture was continuously injected into the chamber.

All experiments were conducted at ambient temperature and relative humidity $<2 \%$. The chamber was manually cleaned between the different experiments to avoid any carryover contaminations, as far as was possible. Background concentrations of aerosols in the chamber varied between 0.5 and $2.0 \mu \mathrm{g} \mathrm{m}^{-3}$.

In the following paragraphs we describe the system for dust generation, measurements of the dust LW spectrum, size distribution, and mineralogy, and data analysis. A summary of the different measured and retrieved quantities in this study and their estimated uncertainties is reported in Table 1. Long-wave optical and size distribution data, acquired at different temporal resolutions, are averaged over $10 \mathrm{~min}$ intervals. Uncertainties on the average values are obtained as the standard deviation over the 10 min intervals. A full description of the SW optical measurements and results is out of the scope of the present study and will be provided in a forthcoming paper (Di Biagio et al., 2017).

\subsection{Dust aerosol generation}

In order to mimic the natural emission process, dust aerosols were generated by mechanical shaking of natural soil samples, as described in DB14. The soils used in this study consist of the surface layer, which is subject to wind erosion in nature (Pye et al., 1987). Prior to each experiment, the soil samples were sieved to $<1000 \mu \mathrm{m}$ and dried at $100^{\circ} \mathrm{C}$ for about $1 \mathrm{~h}$ to remove any residual humidity. This process- ing did not affect the mineral crystalline structure of the soil (Sertsu and Sánchez, 1978).

About $15 \mathrm{~g}$ of soil sample was placed in a Büchner flask and shaken for about $30 \mathrm{~min}$ at $100 \mathrm{~Hz}$ by means of a sieve shaker (Retsch AS200). The dust suspension in the flask was then injected into the chamber by flushing it with $N_{2}$ at $10 \mathrm{~L} \mathrm{~min}^{-1}$ for about $10-15 \mathrm{~min}$, whilst continuously shaking the soil. Larger quantities of soil sample $(60 \mathrm{~g})$ mixed with pure quartz $(60 \mathrm{~g})$ had been used in DB14 to maximize the concentrations of the generated dust. The presence of the pure quartz grains increases the efficiency of the shaking, allowing a rapid generation of high dust concentrations. In that case it had been necessary, however, to pass the aerosol flow through a stainless steel settling cylinder to prevent large quartz grains from entering the chamber (DB14). For the present experiments, the generation system was optimized, i.e., the mechanical system used to fix the flask to the shaker was improved so that the soil shaking was more powerful, and sufficient quantities of dust aerosols could be generated by using a smaller amount of soil and without adding quartz to the soil sample. In this way, the settling cylinder could be eliminated. No differences were observed in the size distribution or mineralogy of the generated dust between the two approaches.

\subsection{LW optical measurements: FTIR extinction spectrum}

The extinction spectrum of dust aerosols in the long wave was measured by means of an in situ FTIR (Bruker ${ }^{\circledR}$ Tensor $37^{\mathrm{TM}}$ ) analytical system. The spectrometer is equipped with a liquid-nitrogen-cooled mercury cadmium telluride (MCT) 
detector and a globar source. The FTIR spectrometer measures between wavelengths of $2.0\left(5000 \mathrm{~cm}^{-1}\right)$ and $16 \mu \mathrm{m}$ $\left(625 \mathrm{~cm}^{-1}\right)$ at $2 \mathrm{~cm}^{-1}$ resolution (which corresponds to a resolution varying from about 0.0008 at $2.0 \mu \mathrm{m}$ wavelength to $0.05 \mu \mathrm{m}$ at $16 \mu \mathrm{m}$ ) by co-adding 158 scans over $2 \mathrm{~min}$. The FTIR spectrometer is interfaced with a multi-pass cell to achieve a total optical path length $(x)$ within the chamber of $192 \pm 4 \mathrm{~m}$. The FTIR reference spectrum was acquired immediately before the dust injection. In some cases small amounts of water vapor and $\mathrm{CO}_{2}$ entered CESAM during particle injection and partly contaminated the dust spectra below $7 \mu \mathrm{m}$. This did not influence the state of particles as the chamber remained very dry (relative humidity $<2 \%$ ). Water vapor and $\mathrm{CO}_{2}$ absorption lines were carefully subtracted using reference spectra. The measured spectra were then interpolated at $0.02 \mu \mathrm{m}$ wavelength resolution (which corresponds to a resolution varying from about 0.8 at $625 \mathrm{~cm}^{-1}$ wavenumber to 50 at $5000 \mathrm{~cm}^{-1}$ ). Due to the excessive loss of energy in the FTIR-measured transmission $(T)$ from 2 to 3 and 15 to $16 \mu \mathrm{m}$, data were limited to the $3-15 \mu \mathrm{m}$ interval. In this spectral range the dust spectral extinction coefficient $\beta_{\text {ext }}$ was calculated as follows:

$\beta_{\text {ext }}(\lambda)=\frac{-\ln (T(\lambda))}{x}$.

The uncertainty on $\beta_{\text {ext }}$ was calculated with the error propagation formula by considering the uncertainties arising from $T$ noise $(\sim 1 \%)$ and from the standard deviation of the 10 min averages and of the path length $x$. We estimated it to be $\sim 10 \%$.

In the $3-15 \mu \mathrm{m}$ range, the dust extinction measured by the FTIR spectrometer is due to the sum of scattering and absorption. Scattering dominates below $6 \mu \mathrm{m}$, while absorption is dominant above $6 \mu \mathrm{m}$. The FTIR multipass cell in the CESAM has been built following the White (1942) design (see Fig. 1). In this configuration, a significant fraction of the light scattered by the dust enters the FTIR detector and is not measured as extinction. This is because mineral dust is dominated by the super-micron fraction, which scatters predominantly in the forward direction. As a consequence, the FTIR signal in the presence of mineral dust will represent only a fraction of dust scattering below $6 \mu \mathrm{m}$ and almost exclusively absorption above $6 \mu \mathrm{m}$. Figure S1 (Supplement), shows an example of the angular distribution of scattered light (phase function) and the scattering-to-absorption ratio calculated as a function of the wavelength in the LW for one of the samples used in this study. The results of the calculations confirm that above $6 \mu \mathrm{m}$ the scattering signal measured by the FTIR spectrometer accounts for less than $20 \%$ of the total LW extinction at the peak of the injection and less than $10 \%$ after $120 \mathrm{~min}$ in the chamber. Consequently, we approximate Eq. (1) as follows:

$\beta_{\mathrm{abs}}(\lambda) \approx \frac{-\ln (T(\lambda))}{x}(\lambda>6 \mu \mathrm{m})$.

\subsection{Size distribution measurements}

The particle number size distribution in the chamber was measured with several instruments, based on different principles and operating in different size ranges:

- a scanning mobility particle sizer (SMPS; TSI, DMA Model 3080, CPC Model 3772; operated at 2.0/0.2 $\mathrm{L} \mathrm{min}^{-1}$ sheath-aerosol flow rates; $135 \mathrm{~s}$ resolution), measuring the dust electrical mobility diameters $\left(D_{\mathrm{m}}\right.$, i.e., the diameter of a sphere with the same migration velocity in a constant electric field as the particle of interest) in the range $0.019-0.882 \mu \mathrm{m}$. Given that dust particles have a density larger than unity (assuming an effective density of $2.5 \mathrm{~g} \mathrm{~cm}^{-3}$ ), the cut point of the impactor at the input of the SMPS shifts towards lower diameters. This reduces the range of measured mobility diameters to $\sim 0.019-0.50 \mu \mathrm{m}$. The SMPS was calibrated prior to the campaign with PSL particles (Thermo Sci.) of $0.05,0.1$, and $0.5 \mu \mathrm{m}$ nominal diameters;

- a WELAS optical particle counter (Palas, model 2000; white light source between 0.35 and $0.70 \mu \mathrm{m}$; flow rate $2 \mathrm{~L} \mathrm{~min}{ }^{-1} ; 60 \mathrm{~s}$ resolution), measuring the dust-sphereequivalent optical diameters $\left(D_{\text {opt }}\right.$, i.e., the diameter of a sphere yielding on the same detector geometry the same optical response as the particle of interest) in the range $0.58-40.7 \mu \mathrm{m}$. The WELAS was calibrated prior to the campaign with Caldust 1100 (Palas) reference particles;

- a SkyGrimm optical particle counter (Grimm Inc., model $1.129 ; 0.655 \mu \mathrm{m}$ operating wavelength; flow rate $1.2 \mathrm{~L} \mathrm{~min}^{-1}$; $6 \mathrm{~s}$ resolution), measuring the dust-sphereequivalent optical diameters $\left(D_{\text {opt }}\right)$ in the range $0.25-$ $32 \mu \mathrm{m}$. The SkyGrimm was calibrated after the campaign against a "master" Grimm (model 1.109) just recalibrated at the factory.

The SMPS and the WELAS were installed at the bottom of the chamber, while the SkyGrimm was installed at the top of the chamber on the same horizontal plane as the FTIR spectrometer and at about $60 \mathrm{~cm}$ across the chamber from the WELAS and the SMPS. As already discussed in DB14, measurements at the top and bottom of the chamber were in very good agreement during the whole duration of each experiment, which indicates a good homogeneity of the dust aerosols in the chamber.

\subsubsection{Corrections of SMPS, WELAS, and SkyGrimm data}

Different corrections have to be applied to the instruments measuring the particle size distribution. For the SMPS, corrections for particle loss by diffusion in the instrument tubing and the contribution of multiple-charged particles were 
performed using the SMPS software. The electrical mobility diameter measured by the SMPS was converted to a geometrical diameter $\left(D_{\mathrm{g}}\right)$ by taking into account the particle dynamic shape factor $(\chi)$, as $D_{\mathrm{g}}=D_{\mathrm{m}} / \chi$. The shape factor $\chi$, determined by comparison with the SkyGrimm in the overlapping particle range $(\sim 0.25-0.50 \mu \mathrm{m})$, was found to be $1.75 \pm 0.10$. This value is higher than those reported in the literature for mineral dust (1.1-1.6; e.g., Davies, 1979; Kaaden et al., 2008). The uncertainty in $D_{\mathrm{g}}$ was estimated with the error propagation formula and was $\sim 6 \%$.

For the WELAS, optical diameters were converted to sphere-equivalent geometrical diameters $\left(D_{\mathrm{g}}\right)$ by taking into account the visible complex refractive index. The $D_{\text {opt }}$ to $D_{\mathrm{g}}$ diameter conversion was performed based on the range of values reported in the literature for dust in the visible range, i.e., $1.47-1.53$ for the real part and $0.001-0.005$ for the imaginary part (Osborne et al., 2008; Otto et al., 2009; McConnell et al., 2010; Kim et al., 2011; Klaver et al., 2011). Optical calculations were computed over the spectral range of the WELAS using Mie theory for spherical particles by fixing $n$ at $1.47,1.50$, and 1.53 , and by varying $k$ in steps of 0.001 between 0.001 and 0.005 . The spectrum of the WELAS lamp needed for optical calculations was measured in the laboratory (Fig. S2). $D_{\mathrm{g}}$ was then set at the mean \pm 1 standard deviation of the values obtained for the different $n$ and $k$. After calculations, the WELAS $D_{\mathrm{g}}$ range became $0.65-73.0 \mu \mathrm{m}$ with an associated uncertainty of $<5 \%$ for $D_{\mathrm{g}}<10 \mu \mathrm{m}$ and between 5 and $7 \%$ at larger diameters. A very low counting efficiency was observed for the WELAS below $1 \mu \mathrm{m}$; thus data in this size range were discarded.

For the SkyGrimm, the $D_{\text {opt }}$ to $D_{\mathrm{g}}$ diameter conversion was performed with a procedure similar to that used for the WELAS. After calculations, the $D_{\mathrm{g}}$ range for the SkyGrimm became $0.29-68.2 \mu \mathrm{m}$ with an associated uncertainty $<15.2 \%$ at all diameters. The inter-calibration between the SkyGrimm and the master instrument showed relatively good agreement $(<20 \%$ difference in particle number) at $D_{\mathrm{g}}<1 \mu \mathrm{m}$, but a large disagreement (up to $300 \%$ difference) at $D_{\mathrm{g}}>1 \mu \mathrm{m}$. Based on inter-comparison data, a recalibration curve was calculated for the SkyGrimm in the range $D_{\mathrm{g}}<1 \mu \mathrm{m}$, and the data for $D_{\mathrm{g}}>1 \mu \mathrm{m}$ were discarded. The SkyGrimm particle concentration was also corrected for the flow rate of the instrument, which during the experiment was observed to vary between 0.7 and $1.2 \mathrm{~L} \mathrm{~min}^{-1}$ compared to its nominal value at $1.2 \mathrm{~L} \mathrm{~min}^{-1}$.

\subsubsection{Correction for particle losses in sampling lines and determination of the full dust size distribution at the input of each instrument}

In order to compare and combine extractive measurements (size distribution, filter sampling, and SW optics), particle losses due to aspiration and transmission in the sampling lines were calculated using the particle loss calculator (PLC) software (von der Weiden et al., 2009). Inputs to the software include the geometry of the sampling line, the sampling flow rate, the particle shape factor $\chi$, and the particle density (set at $2.5 \mathrm{~g} \mathrm{~cm}^{-3}$ for dust).

Particle losses for the instruments measuring the number size distribution (SMPS, WELAS, and SkyGrimm) were calculated. This allowed the reconstruction of the dust size distribution suspended in the CESAM that corresponds to the size distribution sensed by the FTIR spectrometer and that is needed for optical calculations in the LW. Particle loss was found to be negligible at $D_{\mathrm{g}}<1 \mu \mathrm{m}$, reaching $50 \%$ at $D_{\mathrm{g}} \sim 5 \mu \mathrm{m}, 75 \%$ at $D_{\mathrm{g}} \sim 6.3 \mu \mathrm{m}$, and $95 \%$ at $D_{\mathrm{g}} \sim 8 \mu \mathrm{m}$ for the WELAS, the only instrument considered in the supermicron range. Data for the WELAS were then corrected as follows:

$$
\begin{aligned}
& {\left[\mathrm{d} N / \mathrm{d} \log D_{\mathrm{g}}\right]_{\text {Corr,WELAS }}=\left[\mathrm{d} N / \mathrm{d} \log D_{\mathrm{g}}\right]_{\text {WELAS }} /} \\
& \quad \times\left[1-L_{\text {WELAS }}\left(D_{\mathrm{g}}\right)\right]
\end{aligned}
$$

where $\left[\mathrm{d} N / \mathrm{d} \log D_{\mathrm{g}}\right]_{\text {WELAS }}$ is the size measured by the WELAS and $L_{\text {WELAS }}\left(D_{\mathrm{g}}\right)$ is the calculated particle loss as a function of the particle diameter. Data at $D_{\mathrm{g}}>8 \mu \mathrm{m}$, for which the loss is higher than $95 \%$, were excluded from the dataset due to their large uncertainty. The uncertainty on $L_{\text {WELAS }}\left(D_{\mathrm{g}}\right)$ was estimated with a sensitivity study by varying the PLC software values of the input parameters within their uncertainties. The $L_{\text {WELAS }}\left(D_{\mathrm{g}}\right)$ uncertainty varies between $\sim 50 \%$ at $2 \mu \mathrm{m}$ and $\sim 10 \%$ at $8 \mu \mathrm{m}$. The total uncertainty in the WELAS-corrected size distribution was estimated as the combination of the $\mathrm{d} N / \mathrm{d} \log D_{\mathrm{g}}$ standard deviation on the $10 \mathrm{~min}$ average and the $L_{\text {WELAS }}\left(D_{\mathrm{g}}\right)$ uncertainty.

The full size distribution of dust aerosols within the CE$\mathrm{SAM},\left[\mathrm{d} N / \mathrm{d} \log D_{\mathrm{g}}\right]_{\mathrm{CESAM}}$, was determined by combining SMPS and SkyGrimm data with WELAS loss-corrected data: the SMPS was taken at $D_{\mathrm{g}}<0.3 \mu \mathrm{m}$, the SkyGrimm at $D_{\mathrm{g}}=0.3-1.0 \mu \mathrm{m}$, and the WELAS at $D_{\mathrm{g}}=1.0-8.0 \mu \mathrm{m}$. Data were then interpolated in steps of $\operatorname{d} \log D_{\mathrm{g}}=0.05$. An example of the size distributions measured by the different instruments is shown in Fig. S3. Above $8 \mu \mathrm{m}$, where WELAS data were not available, the dust size distribution was extrapolated by applying a single-mode lognormal fit. The fit was set to reproduce the shape of the WELAS distribution between $D_{\mathrm{g}} \sim 3-4$ and $8 \mu \mathrm{m}$.

Particle losses in the filter sampling system $\left(L_{\text {filter }}\left(D_{\mathrm{g}}\right)\right)$ were calculated estimating the size-dependent particles losses that would be experienced by an aerosol with the size distribution in CESAM reconstructed from the previous calculations. Losses for the sampling filter were negligible for $D_{\mathrm{g}}<1 \mu \mathrm{m}$, and increased to $50 \%$ at $D_{\mathrm{g}} \sim 6.5 \mu \mathrm{m}, 75 \%$ at $D_{\mathrm{g}} \sim 9 \mu \mathrm{m}$, and $95 \%$ at $D_{\mathrm{g}} \sim 12 \mu \mathrm{m}$. The loss function, $L_{\text {filter }}$ $\left(D_{\mathrm{g}}\right)$, was used to estimate the dust size distribution at the input of the filter sampling system as follows. 


$$
\begin{aligned}
{\left[\mathrm{d} N / \mathrm{d} \log D_{\mathrm{g}}\right]_{\text {filter }} } & =\left[\mathrm{d} N / \mathrm{d} \log D_{\mathrm{g}}\right]_{\text {CESAM }} \\
& \times\left[1-L_{\text {filter }}\left(D_{\mathrm{g}}\right)\right]
\end{aligned}
$$

As a consequence of losses, the FTIR spectrometer and the filters sense particles over different size ranges. Figure S4 illustrates this point by showing a comparison between the calculated size distribution within CESAM and that sampled on filters for one typical case. An underestimation of the particle number on the sampling filter compared to that measured in CESAM is observed above $10 \mu \mathrm{m}$ diameter. While the filter samples would underestimate the mass concentration in the chamber, the relative proportions of the main minerals should be well represented. As a matter of fact, at emission, where particles of diameters above $10 \mu \mathrm{m}$ are most relevant, the mineralogical composition in the 10-20 $\mu \mathrm{m}$ size class matches that of particles of diameters between 5 and $10 \mu \mathrm{m}$ (Kandler et al., 2009). When averaging, and also taking into account the contribution of the mass of the 10-20 $\mu \mathrm{m}$ size class to the total, differences in the relative proportions of minerals do not exceed $10 \%$.

\subsection{Analysis of the mineralogical composition of the dust aerosol}

The mineralogical composition of the aerosol particles collected on the filters was determined by combining the following techniques: X-ray diffraction (XRD, Panalytical model Empyrean diffractometer) to estimate the particles' mineralogical composition in terms of clays, quartz, calcite, dolomite, gypsum, and feldspars; wavelength dispersive $\mathrm{x}$ ray fluorescence (WD-XRF, Panalytical PW-2404 spectrometer) to determine the dust elemental composition $(\mathrm{Na}, \mathrm{Mg}$, $\mathrm{Al}, \mathrm{Si}, \mathrm{P}, \mathrm{K}, \mathrm{Ca}, \mathrm{Ti}, \mathrm{Fe} ; \pm 8-10 \%$ uncertainty); and X-ray absorption near-edge structure (XANES) to retrieve the content of iron oxides ( $\pm 15 \%$ on the mass fraction) and their speciation between hematite and goethite. Half of the Nuclepore filters were analyzed by XRD and the other half by WD-XRF and XANES. Full details on the WD-XRF and XANES measurements and data analysis are provided elsewhere (Caponi et al., 2017). Here we describe the XRD measurements.

XRD analysis was performed using a Panalytical model Empyrean diffractometer with $\mathrm{Ni}$-filtered $\mathrm{CuK}_{\alpha}$ radiation at $45 \mathrm{kV}$ and $40 \mathrm{~mA}$. Samples were scanned from 5 to $60^{\circ}$

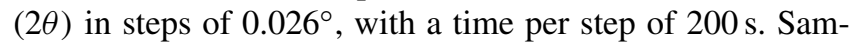
ples were prepared and analyzed according to the protocols of Caquineau et al. (1997) for low mass loadings (load deposited on filter $<800 \mu \mathrm{g}$ ). Particles were first extracted from the filter with ethanol, then concentrated by centrifuging $(25000 \mathrm{rpm}$ for $30 \mathrm{~min})$, diluted with deionized water ( $\mathrm{pH} \sim 7.1)$, and finally deposited on a pure silicon slide.

For well crystallized minerals, such as quartz, calcite, dolomite, gypsum, and feldspars (orthoclase, albite), a mass calibration was performed in order to establish the relationship between the intensity of the diffraction peak and the mass concentration in the aerosol samples, according to the procedure described in Klaver et al. (2011). The calibration coefficients $K_{i}$, representing the ratio between the total peak surface area in the diffraction spectra $\left(S_{i}\right)$ and the mass $m_{i}$ of the $i$ th-mineral, are reported in Table S1 in the Supplement. The error in the obtained mass of each mineral was estimated with the error propagation formula taking into account the uncertainty in $S_{i}$ and the calibration coefficients $K_{i}$. The obtained uncertainty is $\pm 9 \%$ for quartz, $\pm 14 \%$ for orthoclase, $\pm 8 \%$ for albite, $\pm 11 \%$ for calcite, $\pm 10 \%$ for dolomite, and $\pm 18 \%$ for gypsum.

Conversely, the mass concentration of clays (kaolinite, illite, smectite, palygorskite, chlorite), also detected in the samples, cannot be quantified in absolute terms from the XRD spectra due to the absence of appropriate calibration standards for these components (Formenti et al., 2014). Hence, the total clay mass was estimated as the difference between the total dust mass and the total mass of quartz, calcium-rich species, and feldspars, estimated after XRD calibration, and iron oxides, estimated from XANES. The mass of organic material was neglected in the calculation: its contributions, however, should not exceed $3 \%$ according to the literature (Lepple and Brine, 1976). The total dust mass was calculated in two ways: from the particle size distribution $\left[\mathrm{d} N / \mathrm{d} \log D_{\mathrm{g}}\right]_{\text {filter }}\left(M_{\text {size }}\right.$, by assuming a dust density of $2.5 \mathrm{~g} \mathrm{~cm}^{-3}$ ) and from the estimated elemental composition ( $M_{\text {elemental }}$, as described in Caponi et al., 2017). Our results show that $M_{\text {size }}$ systematically overestimates $M_{\text {elemental }}$. As a result, using $M_{\text {size }}$ or $M_{\text {elemental }}$ would result in different clay mass fractions. In the absence of a way to assess whether $M_{\text {size }}$ or $M_{\text {elemental }}$ is more accurate, we decided to estimate the clay mass for each dust sample as the mean \pm maximum variability of the values obtained by using the two mass estimates, $M_{\text {size }}$ and $M_{\text {elemental }}$. This approach should give a reasonable approximation of the average clay content in the dust samples. The error in the obtained clay mass varies in the range $14-100 \%$. Subsequently, the mass fraction for each mineral was estimated as the ratio of the mass of the mineral divided by the total mass of all minerals.

For the northern African and eastern Asian aerosols only, the mass apportionment between the different clay species was based on literature values of illite-to-kaolinite (I / K) and chlorite-to-kaolinite (Ch / I) mass ratios (Scheuvens et al., 2013; Formenti et al., 2014). For the other samples, only the total clay mass was estimated.

\section{Retrieval of the LW complex refractive indices}

An optical inversion procedure was applied to retrieve the LW complex refractive index $(m=n-i k)$ of the dust aerosols based on the simultaneous measurements of the particle LW spectra and size. Starting from the number size distribution, $\left[\mathrm{d} N / \mathrm{d} \log D_{\mathrm{g}}\right]_{\mathrm{CESAM}}$, the LW absorption coef- 
ficient, $\beta_{\text {abs }}(\lambda)$, measured in CESAM can be calculated as follows:

$$
\begin{array}{r}
\left(\beta_{\text {abs }}(\lambda)\right)_{\text {calc }}=\sum_{D_{\mathrm{g}}} \frac{\pi D_{\mathrm{g}}^{2}}{4} Q_{\mathrm{abs}}\left(m, \lambda, D_{\mathrm{g}}\right) \\
{\left[\frac{\mathrm{d} N}{\mathrm{~d} \log D_{\mathrm{g}}}\right]_{\mathrm{CESAM}} \mathrm{d} \log D_{\mathrm{g}},}
\end{array}
$$

where $Q_{\mathrm{abs}}\left(m, \lambda, D_{\mathrm{g}}\right)$ is the particle absorption efficiency and $\frac{\pi D_{\mathrm{g}}^{2}}{4}\left[\frac{\mathrm{d} N}{\mathrm{~d} \log D_{\mathrm{g}}}\right]_{\text {CESAM }}$ is the surface size distribution of the particles. As the simplest approach, $Q_{\text {abs }}$ can be computed using Mie theory for spherical particles.

Our retrieval algorithm consists of iteratively varying $m$ in Eq. (5) until $\left(\beta_{\text {abs }}(\lambda)\right)_{\text {calc }}$ matches the measured $\beta_{\text {abs }}(\lambda)$. However, as $m$ is a complex number with two variables, an additional condition is needed. According to electromagnetic theory, $n$ and $k$ must satisfy the Kramers-Kronig $(\mathrm{K}-\mathrm{K})$ relationship (Bohren and Huffmann, 1983):

$n(\omega)-1=\frac{2}{\pi} P \int_{0}^{\infty} \frac{\Omega \cdot k(\Omega)}{\Omega^{2}-\omega^{2}} \cdot \mathrm{d} \Omega$,

with $\omega$ the angular frequency of radiation $\left(\omega=2 \pi c / \lambda,\left(\mathrm{s}^{-1}\right)\right)$ and $P$ the principal value of the Cauchy integral. Equation (6) means that if $k(\lambda)$ is known, then $n(\lambda)$ can be calculated accordingly. Hence, the $\mathrm{K}-\mathrm{K}$ relation is the additional condition besides Eq. (5) to retrieve $n$ and $k$. A direct calculation of the $\mathrm{K}-\mathrm{K}$ integral is, however, very difficult as it requires the knowledge of $k$ over an infinite wavelength range. A useful formulation, which permits one to obtain the couple of $n-k$ values that automatically satisfy the K-K condition, is the one based on the Lorentz dispersion theory. In the Lorentz formulation, $n$ and $k$ may be written as a function of the real $\left(\varepsilon_{\mathrm{r}}\right)$ and imaginary $\left(\varepsilon_{\mathrm{i}}\right)$ parts of the particle dielectric function:

$$
\begin{aligned}
& n(\omega)=\left(\frac{1}{2}\left[\sqrt{\left(\varepsilon_{\mathrm{r}}(\omega)\right)^{2}+\left(\varepsilon_{\mathrm{i}}(\omega)\right)^{2}}+\varepsilon_{\mathrm{r}}(\omega)\right]\right)^{1 / 2}, \\
& k(\omega)=\left(\frac{1}{2}\left[\sqrt{\left(\varepsilon_{\mathrm{r}}(\omega)\right)^{2}+\left(\varepsilon_{\mathrm{i}}(\omega)\right)^{2}}-\varepsilon_{\mathrm{r}}(\omega)\right]\right)^{1 / 2} .
\end{aligned}
$$

In turn, $\varepsilon_{\mathrm{r}}(\omega)$ and $\varepsilon_{\mathrm{i}}(\omega)$ can be expressed as the sum of $N$ Lorentzian harmonic oscillators:

$$
\begin{aligned}
& \varepsilon_{\mathrm{r}}(\omega)=\varepsilon_{\infty}+\left[\sum_{j=1}^{N} \frac{F_{j}\left(\omega_{j}^{2}-\omega^{2}\right)}{\left(\omega_{j}^{2}-\omega^{2}\right)^{2}+\gamma_{j}^{2} \omega^{2}}\right] \\
& \varepsilon_{\mathrm{i}}(\omega)=\sum_{j=1}^{N} \frac{F_{j} \gamma_{j} \omega}{\left(\omega_{j}^{2}-\omega^{2}\right)^{2}+\gamma_{j}^{2} \omega^{2}},
\end{aligned}
$$

where $\varepsilon_{\infty}=n_{\text {vis }}^{2}$ is the real dielectric function in the limit of visible wavelengths, $n_{\text {vis }}$ the real part of the refractive index in the visible, and $\omega_{j}, \gamma_{j}$, and $F_{j}$ are the three parameters (eigenfrequency, damping factor, and strength respectively) characterizing the $j$ th oscillator.

In our algorithm we combined Eqs. (7a)-(7b) and (8a)(8b) with Eq. (5) to retrieve $n-k$ values that allow both the reproduction of the measured $\beta_{\mathrm{abs}}(\lambda)$ and the satisfaction of the $\mathrm{K}-\mathrm{K}$ relationship. In practice, in the iteration procedure only one of the two components of the refractive index (in our case, $k$ ) was varied, while the other $(n)$ was recalculated at each step based on the values of the oscillator parameters $\left(\omega_{j}, \gamma_{j}, F_{j}\right)$ obtained from a best fit for $k$. In the calculations, the initial value of $k(\lambda)$ was set at $k(\lambda)=\lambda \beta_{\text {abs }}(\lambda) / 4 \pi$; then in the iteration procedure, $k(\lambda)$ was varied in steps of 0.001 without imposing any constraint on its spectral shape. Initial values of the $\left(\omega_{j}, \gamma_{j}, F_{j}\right)$ parameters were set manually based on the initial spectrum of $k(\lambda)$. Between 6 and 10 oscillators were needed to model the $k(\lambda)$ spectrum for the different cases. The fit between $k(\lambda)$ and Eq. (7b) was performed using the Levenberg-Marquardt technique. The iteration procedure was stopped when the condition: $\left(\mid \beta_{\mathrm{abs}}(\lambda)\right)_{\text {calc }}-\beta_{\mathrm{abs}}(\lambda) \mid<1 \%$ was met at all wavelengths.

Optical calculations were performed between 6 and $15 \mu \mathrm{m}$, within a range where FTIR-measured scattering could be neglected (see Sect. 2.2). The uncertainties caused by this choice are discussed in Sect. 3.1. Below $6 \mu \mathrm{m}, k(\lambda)$ was then fixed to the value obtained at $6 \mu \mathrm{m}$. Calculations were performed over $10 \mathrm{~min}$ intervals.

For each experiment and for each $10 \mathrm{~min}$ interval, the value of $n_{\text {vis }}$ to use in Eq. (8a) was obtained from optical calculations using the simultaneous measurements of the SW scattering and absorption coefficients performed in CESAM (Di Biagio et al., 2017). For the various aerosol samples considered here, the value of $n_{\text {vis }}$ varied between 1.47 and 1.52 with an uncertainty $<2 \%$. This approach is better than the one used in DB14, where the value of $n_{\text {vis }}$ was manually adjusted for successive trials. Specifically, in DB14, $n_{\text {vis }}$ was varied and set to the value that allowed the best reproduction of the measured dust scattering signal below $6 \mu \mathrm{m}$. As discussed in Sect. 2.2, however, only a fraction of the total dust scattering is measured by the FTIR spectrometer. As a result, the $n_{\text {vis }}$ values obtained in DB14 were considerably lower than the values generally assumed for dust $\left(n_{\text {vis }}=1.32-1.35\right.$ compared to 1.47-1.53 from the literature; e.g., Osborne et al., 2008; McConnell et al., 2010), with a possible resulting overall underestimation of $n$. Here, instead, the $n_{\text {vis }}$ value was obtained based on additional SW optical measurements, which ensured a more reliable estimate of the whole spectral $n$.

The validity of the proposed retrieval procedure was assessed by performing a control experiment where ammonium sulfate aerosols were injected in the chamber. Ammonium sulfate has been widely studied in the past and its optical properties are well known (e.g., Toon et al., 1976; Flores et 
al., 2009). The description and the results of the control experiment are reported in Appendix Sect. A.

\subsection{Caveats on the retrieval procedure for the $\mathrm{LW}$ refractive index}

The procedure for the retrieval of the complex refractive index presented in the previous section combines optical calculations, the Kramers-Kronig relation, and the Lorentz dispersion theory, and was based on measurements of spectral absorption and particle size distribution. The approach is quite sensitive to the accuracy and representativeness of the measurements and assumptions in the optical calculations. We now list the different points that need to be addressed to ensure the accuracy of the retrieval procedure.

1. First, our optical calculations (Eq. 5) use Mie theory for spherical particles. This is expected to introduce some degrees of uncertainties in simulated LW spectra, especially near the resonant peaks (Legrand et al., 2014). However, as discussed in Kalashnikova and Sokolik (2004), deviations from spherical behavior are mostly due to the scattering component of extinction since irregularly shaped particles have larger scattering efficiencies than spheres. In contrast, particle absorption is much less sensitive to particle shape. Given that our measured spectra are dominated by absorption, we can therefore reasonably assume that Mie theory is well suited to model our optical data. It also has to be pointed out that at present almost all climate models use Mie theory to calculate dust optical properties. So, with the aim of implementing our retrieved refractive indices in model schemes, it is required that the same optical assumptions are made in both cases, i.e., the optical theory used in models and that used for refractive index retrieval.

2. Second, as discussed in Sect. 2.2, measured dust spectra at wavelengths $>6 \mu \mathrm{m}$ represent only dust absorption, with minimal contribution from scattering. Dufresne et al. (2002) show that the contribution of LW scattering from dust is quite important in the atmosphere, especially under cloudy conditions. Therefore, the impact of neglecting the scattering contribution has to be assessed. The retrieval procedure used in this study is nearly independent of whether dust extinction or absorption only is used. Indeed, the combination of Eq. (5) with the Lorentz formulation in Eq. (7a) and (7b) ensures the retrieval of $n-k$ couples that are theoretically correct (fulfilling the $\mathrm{K}-\mathrm{K}$ relationship), and the specific quantity to reproduce by Eq. (5) - i.e., extinction or absorption provides only a mathematical constraint on the retrieval. Therefore, neglecting the scattering contribution to the LW spectra has no influence on the estimates of the refractive index, and the real and the imaginary parts ob- tained in this study represent both the scattering and the absorption components of the dust extinction.

3. Third, our optical calculations are performed only at wavelengths $>6 \mu \mathrm{m}$, while in the range $3-6 \mu \mathrm{m} k(\lambda)$ is fixed to the value obtained at $6 \mu \mathrm{m}$. We examine the accuracy of this assumption. Given that, over the whole 3-6 $\mu \mathrm{m}$ range, dust is expected to have a negligible absorption ( $k$ is close to zero; see Di Biagio et al., 2014a), fixing $k$ at the value at $6 \mu \mathrm{m}$ is a reasonable approximation. Concerning the impact of this assumption on the retrieval of $n$, it should be pointed out that in the range 3-6 $\mu \mathrm{m}$, where $k$ is very low, the shape of the $n$ spectrum is determined only by the anchor point $n_{\mathrm{vis}}$, and the exact value of $k$ is not relevant.

\subsection{Uncertainty estimation}

The uncertainty in the retrieved refractive index was estimated with a sensitivity analysis. Towards this goal, $n$ and $k$ were also obtained by using, as input to the retrieval algorithm, the measured $\beta_{\text {abs }}(\lambda)$ and size distribution \pm their estimated uncertainties. The differences between the so-obtained $n$ and $k$ and the $n$ and $k$ from the first inversion were estimated. Then, we computed a quadratic combination of these different factors to deduce the uncertainty in $n$ and $k$.

The results of the sensitivity study indicated that the measurement uncertainties on $\beta_{\text {abs }}(\lambda)( \pm 10 \%)$ and the size distribution (absolute uncertainty on the number concentration, $\pm 20-70 \%$, with values larger than $30 \%$ found for diameters between about 0.5 and $2.0 \mu \mathrm{m}$ ) have an impact of $\sim 10-20 \%$ on the retrieval of $n$ and $k$.

Additionally, a sensitivity analysis was performed to test the dependence of the retrieved LW refractive index on the accuracy of the shape of the size distribution above $8 \mu \mathrm{m}$. As discussed in Sect. 2.3.2, the size distribution, $\left[\mathrm{d} N / \mathrm{d} \log D_{\mathrm{g}}\right]_{\text {CESAM }}$, used for the optical calculations was measured between 0.1 and $8 \mu \mathrm{m}$ based on SMPS, SkyGrimm, and WELAS data. However, it was extrapolated to larger sizes by applying a lognormal mode fit for particle diameters $>8 \mu \mathrm{m}$, where measurements were not available. The extrapolation was set to reproduce the shape of the WELAS size distribution between $D_{\mathrm{g}} \sim 3-4$ and $8 \mu \mathrm{m}$. In the sensitivity study, $n$ and $k$ were also obtained by using two different size distributions as input to the retrieval algorithm, in which the extrapolation curve at $D_{\mathrm{g}}>8 \mu \mathrm{m}$ was calculated by considering the WELAS data \pm their estimated $y$ uncertainties. The results of the sensitivity study indicate that a change of the extrapolation curve between its minimum and maximum may induce a variation of less than $10 \%$ on the retrieved $n$ and $k$.

The total uncertainty in $n$ and $k$, estimated as the quadratic combination of these factors, was close to $20 \%$.

An additional source of uncertainty linked to the size distribution, which however we do not quantify here, concerns 
Table 2. Summary of information on the soil samples used in this study.

\begin{tabular}{|c|c|c|c|c|}
\hline Sample name & Collection Coordinates & Geographical zone & Country & Desert zone \\
\hline Tunisia & $33.02^{\circ} \mathrm{N}, 10.67^{\circ} \mathrm{E}$ & Northern Africa & Tunisia & Sahara desert (Maouna) \\
\hline Morocco & $31.97^{\circ} \mathrm{N}, 3.28^{\circ} \mathrm{W}$ & Northern Africa & Morocco & Sahara desert (east of Ksar Sahli) \\
\hline Libya & $27.01^{\circ} \mathrm{N}, 14.50^{\circ} \mathrm{E}$ & Northern Africa & Libya & Sahara desert (Sebha) \\
\hline Algeria & $23.95^{\circ} \mathrm{N}, 5.47^{\circ} \mathrm{E}$ & Northern Africa & Algeria & Sahara desert (Ti-n-Tekraouit) \\
\hline Mauritania & $20.16^{\circ} \mathrm{N}, 12.33^{\circ} \mathrm{W}$ & Northern Africa & Mauritania & Sahara desert (east of Aouinet Nchir) \\
\hline Niger & $13.52^{\circ} \mathrm{N}, 2.63^{\circ} \mathrm{E}$ & Sahel & Niger & Sahel (Banizoumbou) \\
\hline Mali & $17.62^{\circ} \mathrm{N}, 4.29^{\circ} \mathrm{W}$ & Sahel & Mali & Sahel (Dar el Beida) \\
\hline Bodélé & $17.23^{\circ} \mathrm{N}, 19.03^{\circ} \mathrm{E}$ & Sahel & Chad & Bodélé depression \\
\hline Ethiopia & $7.50^{\circ} \mathrm{N}, 38.65^{\circ} \mathrm{E}$ & $\begin{array}{l}\text { Eastern Africa and } \\
\text { the Middle East }\end{array}$ & Ethiopia & Lake Shala National Park \\
\hline Saudi Arabia & $27.49^{\circ} \mathrm{N}, 41.98^{\circ} \mathrm{E}$ & $\begin{array}{l}\text { Eastern Africa and } \\
\text { the Middle East }\end{array}$ & Saudi Arabia & Nefud desert \\
\hline Kuwait & $29.42^{\circ} \mathrm{N}, 47.69^{\circ} \mathrm{E}$ & $\begin{array}{l}\text { Eastern Africa and } \\
\text { the Middle East }\end{array}$ & Kuwait & Kuwaiti desert \\
\hline Gobi & $39.43^{\circ} \mathrm{N}, 105.67^{\circ} \mathrm{E}$ & Eastern Asia & China & Gobi desert \\
\hline Taklimakan & $41.83^{\circ} \mathrm{N}, 85.88^{\circ} \mathrm{E}$ & Eastern Asia & China & Taklimakan desert \\
\hline Arizona & $33.15^{\circ} \mathrm{N}, 112.08^{\circ} \mathrm{W}$ & North America & Arizona & Sonoran desert \\
\hline Atacama & $23.72^{\circ} \mathrm{S}, 70.40^{\circ} \mathrm{W}$ & South America & Chile & Atacama desert \\
\hline Patagonia & $50.26^{\circ} \mathrm{S}, 71.50^{\circ} \mathrm{W}$ & South America & Argentina & Patagonian desert \\
\hline Namib-1 & $21.24^{\circ} \mathrm{S}, 14.99^{\circ} \mathrm{E}$ & Southern Africa & Namibia & $\begin{array}{l}\text { Namib desert (area between the } \\
\text { Kuiseb and Ugab valleys) }\end{array}$ \\
\hline Namib-2 & $19.0^{\circ} \mathrm{S}, 13.0^{\circ} \mathrm{E}$ & Southern Africa & Namibia & $\begin{array}{l}\text { Namib desert (Damaraland, rocky } \\
\text { area in north-western Namibia) }\end{array}$ \\
\hline Australia & $31.33^{\circ} \mathrm{S}, 140.33^{\circ} \mathrm{E}$ & Australia & Australia & Strzelecki Desert \\
\hline
\end{tabular}

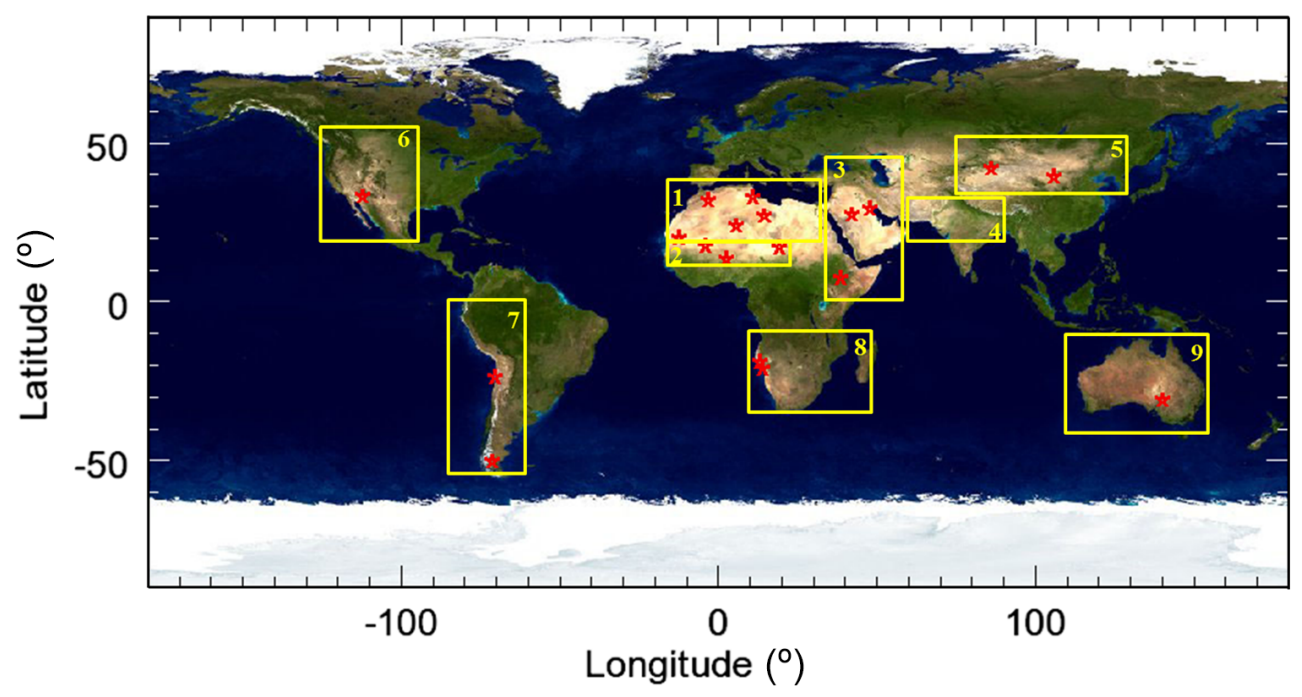

Figure 2. Location (red stars) of the soil and sediment samples used to generate dust aerosols. The nine yellow rectangles depict the different global dust source areas as defined in Ginoux et al. (2012): (1) northern Africa, (2) the Sahel, (3) eastern Africa and Middle East, (4) central Asia, (5) eastern Asia, (6) North America, (7) South America, (8) southern Africa, and (9) Australia.

the choice of performing a single-mode extrapolation above $8 \mu \mathrm{m}$, which means neglecting the possible presence of larger dust modes.

\section{Selection of soil samples: representation of the dust mineralogical variability at the global scale}

A total of 19 soil samples were selected for experiments from a collection of 137 soils from various source areas worldwide. Their location is shown in Fig. 2. The main information 
on the provenance of the selected soils is summarized in Table 2. Soils were grouped in the nine regions identified by $\mathrm{Gi}-$ noux et al. (2012): northern Africa, the Sahel, eastern Africa and Middle East, central Asia, eastern Asia, North America, South America, southern Africa, and Australia. The choice of which soils to analyze was made according to two criteria: (1) soils had to represent all major arid and semi-arid regions, as depicted by Ginoux et al. (2012) and (2) their mineralogy should envelop the largest possible variability of the soil mineralogical composition at the global scale.

A large set of soils were available for northern Africa, the Sahel, eastern Africa and the Middle East, eastern Asia, and southern Africa. Here, the selection was performed using as guidance the global database of Journet et al. (2014), reporting the composition of the clay $(<2 \mu \mathrm{m}$ diameter) and silt ( $<60 \mu \mathrm{m}$ diameter) fractions in terms of 12 different minerals. Amongst them, we analyzed the variability of the minerals that are most abundant in dust as well as most optically relevant to LW absorption, namely illite, kaolinite, calcite, and quartz in the clay fraction, and calcite and quartz in the silt fraction. The comparison of the clay and silt compositions of the soils extracted from the Journet database with the available samples resulted in the selection of five samples for northern Sahara, three for the Sahel, three for eastern Africa and the Middle East, and two for eastern Asia and southern Africa, as listed in Table 2. These soils constitute 15 of the 19 samples used in the experiments. More information on these soils is provided in the following.

For northern Africa, we selected soils from the northern Sahara (Tunisia, Morocco), which are richer in calcite and illite, central Sahara (Libya and Algeria), which are enriched in kaolinite compared to illite and poor in calcite, and western Sahara (Mauritania), which are richer in kaolinite. The three samples from the Sahel are from Niger, Mali, and Chad (sediment from the Bodélé depression), and are enriched in quartz compared to Saharan samples. The selected soils from northern Africa and the Sahel represent important sources for medium- and long-range dust transport towards the Mediterranean (Israelevich et al., 2002) and the Atlantic Ocean (Prospero et al., 2002; Reid et al., 2003). In particular, the Bodélé depression is one of the most active sources at the global scale (Goudie and Middleton, 2001; Washington et al., 2003).

The three soils from eastern Africa and the Middle East are from Ethiopia, Saudi Arabia, and Kuwait, which are important sources of dust in the Red and Arabian seas (Prospero et al., 2002) and the North Indian Ocean (Leon and Legrand, 2003). These three samples differ in their content of calcite, quartz, and illite-to-kaolinite mass ratio (I / K).

For the second-largest global source of dust, eastern Asia, we considered two samples representative of the Gobi and the Taklimakan deserts, respectively. These soils differ in their content of calcite and quartz. Unfortunately, no soils are available for central Asia, mostly due to the difficulty of sampling these remote desert areas.
For southern Africa, we selected two soils from the Namib desert, one soil from the area between the Kuiseb and Ugab valleys (Namib-1) and one soil from the Damaraland rocky area (Namib-2), both sources of dust transported towards the south-eastern Atlantic (Vickery et al., 2013). These two soils present different compositions in term of calcite content and I / K ratio.

In contrast to Africa, the Middle East, and eastern Asia, a very limited number of samples were available in the soil collection for North and South America and Australia. Of the 19 soils used in our experiments, 4 were taken from these regions. These soils were collected in the Sonoran Desert for North America, in the Atacama and Patagonian deserts for South America, and in the Strzelecki desert for Australia. The Sonoran Desert is a permanent source of dust in North America, the Atacama desert is the most important source of dust in South America, whilst Patagonia emissions are relevant for long-range transport towards Antarctica (Ginoux et al., 2012). The Strzelecki desert is the seventh largest desert of Australia. No mineralogical criteria were applied to these areas.

A summary of the mineralogical composition of the 19 selected soils is shown in Fig. 3 in comparison with the full range of variability obtained considering the full data from the 9 different dust source areas. As illustrated by this figure, the samples chosen for this study cover the entire global variability of the soil compositions derived by Journet et al. (2014).

\section{Results}

\subsection{Atmospheric representativity: mineralogical composition}

The mineralogical composition measured for the 19 aerosol samples is shown in Fig. 4. Data on the full mineralogy, also including the minimum and the maximum of the estimated dust clay content, are provided in Table $\mathrm{S} 2$ in the supporting material. The aerosol composition is dominated by clays ( $\sim 46-92 \%$ for the different samples), with variable contents of quartz, calcite, dolomite, and feldspars. Identified clay species are illite, kaolinite, smectite, palygorskite, and chlorite. Illite and kaolinite are ubiquitous; smectite and palygorskite are detected in some of the samples (Algeria, Ethiopia, Saudi Arabia, Kuwait, Arizona, and both samples from Namibia); in contrast, chlorite is found only in the two Chinese samples and in the Chilean samples. The estimated contribution of illite, kaolinite, and chlorite to the total clay mass is shown in Fig. 4 for northern Africa (Algerian sample excluded, given that smectite is also detected in this sample) and eastern Asian aerosols. Quartz ranges from 3 to $42 \%$ by mass in the samples, with the highest values measured for Patagonia, Niger, Australia, Mali, and Bodélé dust. Calcite is less than $23 \%$, with maxima observed for Tunisia, 

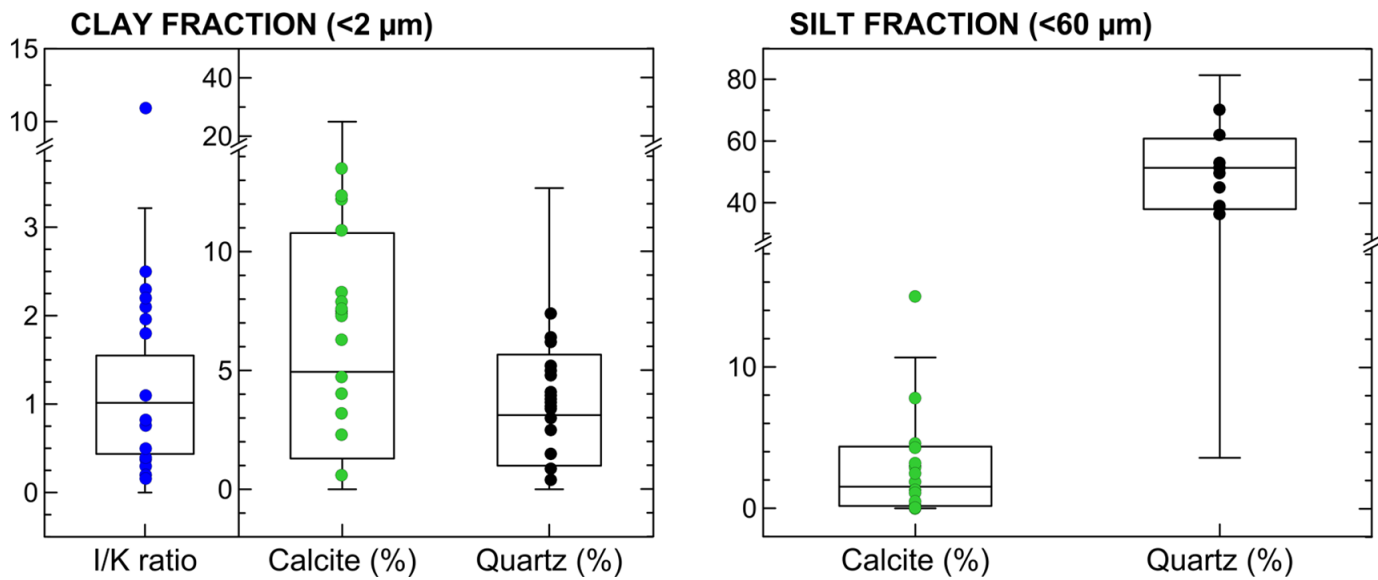

Figure 3. Box and whisker plots showing the variability of the soil composition in the clay and silt fractions at the global scale, i.e., by considering all data from the nine dust source areas identified in Fig. 2. Data are from the soil mineralogical database by Journet et al. (2014). Dots indicate specific mineralogical characteristics (illite-to-kaolinite mass ratio (I / K), calcite and quartz contents, extracted from Journet et al., 2014) of the soils used in the CESAM experiments, as listed in Table 2.

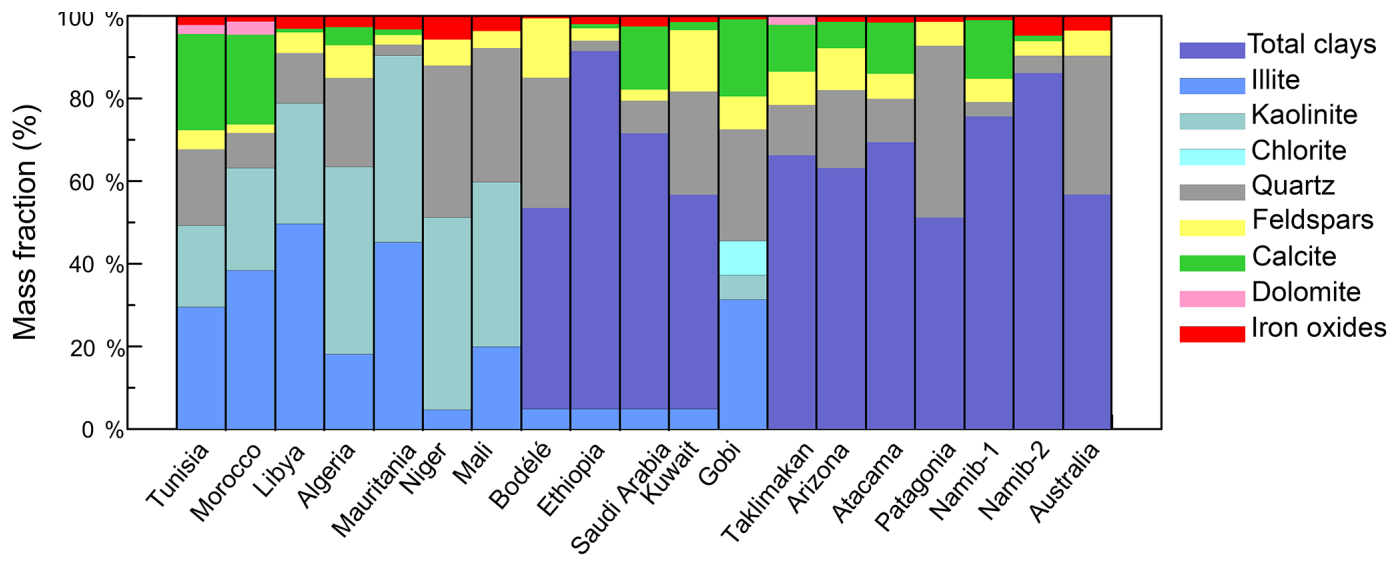

Figure 4. Mineralogy of the 19 generated aerosol samples considered in this study. The mass apportionment between the different clay species (illite, kaolinite, chlorite) is shown for northern African (Tunisia, Morocco, Libya, Mauritania, Niger, Mali, Bodélé) and eastern Asian (Gobi, Taklimakan) aerosols based on compiled literature values of the illite-to-kaolinite (I / K) and chlorite-to-kaolinite (Ch / I) mass ratios (Scheuvens et al., 2013; Formenti et al., 2014). For all other samples only the total clay mass is reported.

Morocco, and Gobi dusts. Conversely, only minor traces of dolomite $(<3 \%)$ are detected in all the different samples. Finally, feldspars (orthoclase and albite) represent less than $15 \%$ of the dust composition.

The observations from the present study capture well the global tendencies of the dust mineralogical compositions as observed in several studies based on aerosol field observations, both from ground-based and airborne samples (e.g., Sokolik and Toon, 1999; Caquineau et al., 2002; Shen et al., 2005; Jeong, 2008; Kandler et al., 2009; Scheuvens et al., 2013; Formenti et al., 2014). For instance, at the scale of northern Africa, we correctly reproduce the geographical distribution of calcite, which is expected to be larger in northern Saharan samples (Tunisia, Morocco), and very low or absent when moving towards the southern part of the Sa- hara and the Sahel (Libya, Algeria, Mauritania, Niger, Mali, and Bodélé). Similarly, we observe an increase of the aerosol quartz content from the northern Sahara towards the Sahel, which is well known at the regional scale of northern Africa (e.g., Caquineau et al., 2002). Also, we identify the presence of chlorite in the eastern Asian samples (Gobi and Taklimakan), in agreement with field observations in this region (Shen et al., 2005). A more direct comparison of our data with field measurements of the dust mineralogical composition is rather complicated due to possible differences linked to the size distribution and representativeness of the specific sources between our data and field measurements (Perlwitz et al., 2015). For the Niger sample only, however, a semiquantitative comparison can be performed against field data of the dust mineralogy obtained for aerosols collected at Ban- 

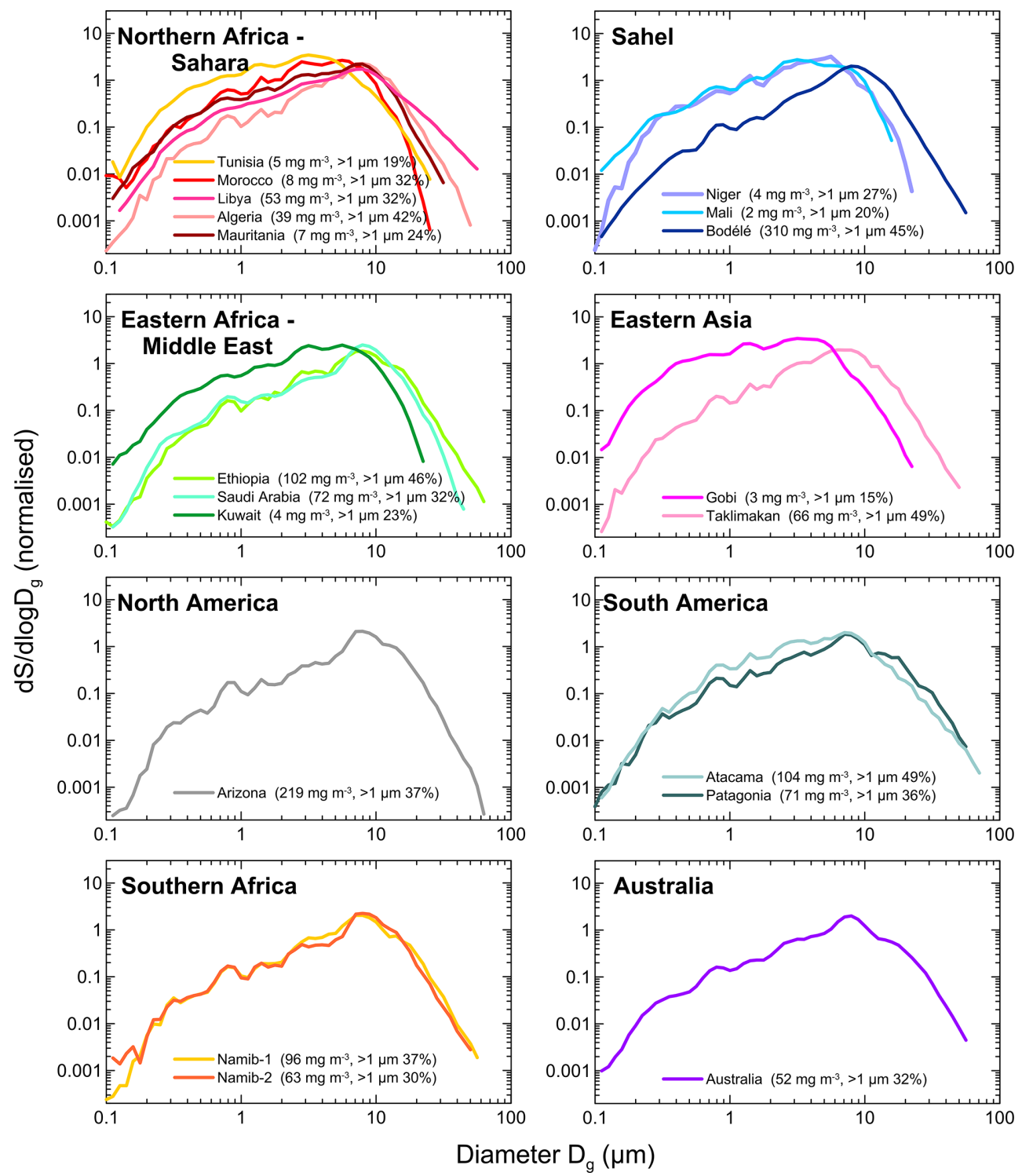

Figure 5. Surface size distributions in the CESAM at the peak of dust injection for all cases analyzed in this study; the total measured dust mass concentration and the percentage of the super-micron to sub-micron number fraction at the peak are also reported in the legend.

izoumbou during the AMMA (African Monsoon Multidisciplinary Analysis) campaign in 2006. The mineralogy for these samples was provided by Formenti et al. (2014). For a case of intense local erosion at Banizoumbou, they showed that the aerosol is composed of $51 \%$ (by volume) clays, $41 \%$ quartz, and $3 \%$ feldspars. Our Niger sample, generated from the soil collected at Banizoumbou, is composed of $51 \%( \pm 5.1 \%$; by mass) clays, $37 \%( \pm 3 \%)$ quartz, and $6 \%$ $( \pm 0.8 \%)$ feldspars, in very good agreement with the field observations.

\subsection{Atmospheric representativity: size distribution}

The size distribution of the dust aerosols measured at the peak of the dust injection in the chamber is shown in Fig. 5.
We report in the plot the normalized surface size distribution, defined as follows:

$$
\begin{aligned}
& \frac{\mathrm{d} S}{\mathrm{~d} \log D_{\mathrm{g}}}(\text { normalized })= \\
& \frac{1}{S_{\mathrm{tot}}} \cdot\left(\frac{\pi}{4} D_{\mathrm{g}}^{2}\left[\mathrm{~d} N / \mathrm{d} \log D_{\mathrm{g}}\right]_{\mathrm{CESAM}}\right),
\end{aligned}
$$

with $S_{\text {tot }}$ the total surface area. The surface size distribution is the quantity that determines dust optical properties (see Eq. 5). The dust surface size distributions present multimodal structures, where the relative proportions of the different modes vary significantly between the samples. The dust mass concentration at the peak of the injection estimated from size distribution data varies between 2 and $310 \mathrm{mg} \mathrm{m}^{-3}$. 


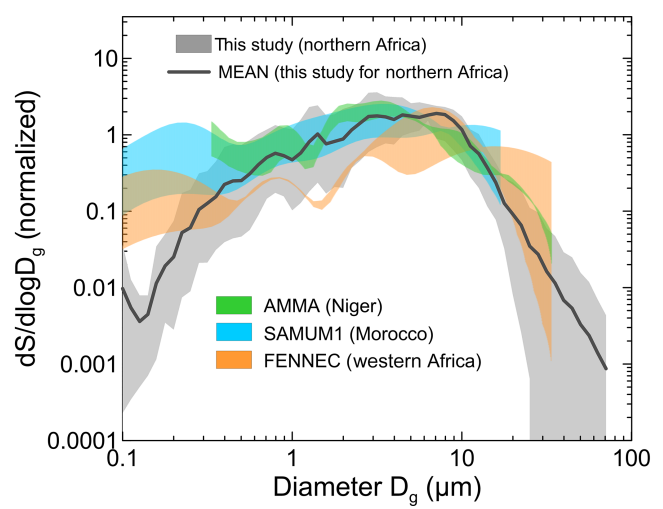

Figure 6. Comparison of CESAM measurements at the peak of the injection with dust size distributions from several airborne field campaigns in northern Africa. The grey shaded area represents the range of sizes measured in CESAM during experiments with the different northern African samples. Data from field campaigns are: AMMA (Formenti et al., 2011), SAMUM-1 (Weinzierl et al., 2009), and FENNEC (Ryder et al., 2013a). The shaded areas for each dataset correspond to the range of variability observed for the campaigns considered.

These values are comparable to what has been observed close to sources in proximity to dust storms (Goudie and Middleton, 2006; Rajot et al., 2008; Kandler et al., 2009; Marticorena et al., 2010). Given that the protocol used for soil preparation and aerosol generation is always the same for the different experiments, the observed differences in both the shape of the size distribution and the mass concentration of the generated dust aerosols are attributable to the specific characteristics of the soils, which may be more or less prone to producing coarse-size particles.

The comparison of the chamber data with observations of the dust size distribution from several airborne campaigns in Africa is shown in Fig. 6. This comparison suggests that the shape of the size distribution in the chamber at the peak of the injection accurately mimics the dust distribution in the atmosphere near sources.

The time evolution of the normalized surface size distribution within CESAM is shown in Fig. 7 for two examples taken from the Algeria and Atacama experiments, while an example of the dust number and mass concentration evolution over an entire experiment is illustrated in Fig. S5. The Algeria and Atacama samples were chosen as representative of different geographic areas and different concentration levels in the chamber. As shown in Fig. 7, the dust size distribution strongly changes with time due to gravitational settling: the coarse mode above $5 \mu \mathrm{m}$ rapidly decreases, due to the larger fall speed at these sizes $\left(\sim 1 \mathrm{~cm} \mathrm{~s}^{-1}\right.$ at $10 \mu \mathrm{m}$, compared to $\sim 0.01 \mathrm{~cm} \mathrm{~s}^{-1}$ at $1 \mu \mathrm{m}$; Seinfeld and Pandis, 2006), and the relative importance of the fraction smaller than $D_{\mathrm{g}}=5 \mu \mathrm{m}$ increases concurrently. In the chamber we are thus able to reproduce very rapidly (in about $2 \mathrm{~h}$ ) the size-selective gravitational settling, a process that in the at- mosphere may take about 1 to 5 days to occur (Maring et al., 2003). In order to compare the dust gravitational settling in the chamber with that observed in the atmosphere, the following analysis was performed. For both Algeria and Atacama soils, the fraction of particles remaining in suspension in the chamber as a function of time versus particle size was calculated as $\mathrm{d} N_{i}\left(D_{\mathrm{g}}\right) / \mathrm{d} N_{0}\left(D_{\mathrm{g}}\right)$, where $\mathrm{d} N_{i}\left(D_{\mathrm{g}}\right)$ is the number of particles measured by size class at time $i$ ( $i$ corresponding to $30,60,90$, and $120 \mathrm{~min}$ after injection) and $\mathrm{d} N_{0}\left(D_{\mathrm{g}}\right)$ represents the size-dependent particle number at the peak of the injection. The results of these calculations are shown in the lower panels of Fig. 7, where they are compared to the fraction remaining airborne after 1-2 days obtained in the field study by Ryder et al. (2013b) for mineral dust transported out of northern Africa in the Saharan air layer (Karyampudi et al., 1999), that is, at altitudes between 1.5 and $6 \mathrm{~km}$ above sea level. The comparison indicates that the remaining particle fraction observed $30 \mathrm{~min}$ after the peak of the injection is comparable to that obtained by Ryder et al. (2013b) for particles between $\sim 0.4$ and $3 \mu \mathrm{m}$ for the Algeria case, and $\sim 0.4$ and $8 \mu \mathrm{m}$ for the Atacama case, but that the depletion is much faster for both smaller and larger particles. This suggests, on the one hand, that the number fraction of coarse particles in the chamber depends on the initial size distribution, that is, on the nature of the soil itself. On the other hand, it shows the limitation of the four-blade fan in providing a vertical updraft sufficient to counterbalance the gravimetric deposition for particles larger than about $8 \mu \mathrm{m}$. This point, however, is not surprising since it is clear that in the laboratory it is not possible to reproduce the wide range of dynamical processes that occur in the real atmosphere, and so to obtain a faithful reproduction of dust gravitational settling and the counteracting re-suspension mechanisms. Nonetheless, it should be noted that the rate of removal is higher at the earlier stages of the experiments than towards their end. The size-dependent particle lifetime, defined as the value at which $\mathrm{d} N / \mathrm{d} N_{0}$ is equal to $1 / e$ (McMurry and Rader, 1985), is relatively invariant for particles smaller than $D_{\mathrm{g}}<\sim 2 \mu \mathrm{m}(>60 \mathrm{~min})$. This indicates that no significant distortion of the particle size distribution occurs after the most significant removal at the beginning of the experiment, and that the fine-to-coarse proportions are modified with time in a manner consistent with previous field observations on medium- to long-transport (e.g., Maring et al., 2003; Rajot et al., 2008; Reid et al., 2008; Ryder et al., 2013b; Denjean et al., 2016).

\subsection{Dust LW extinction and complex refractive index spectra for the different source regions}

Figure 8 shows the dust LW spectral extinction coefficients measured at the peak of the injection for the 19 aerosol samples. As discussed in Sect. 2.2, the spectra in Fig. 8 show the contribution of dust scattering below $6 \mu \mathrm{m}$, while the absorption spectrum only is measured above $6 \mu \mathrm{m}$. In this wave- 

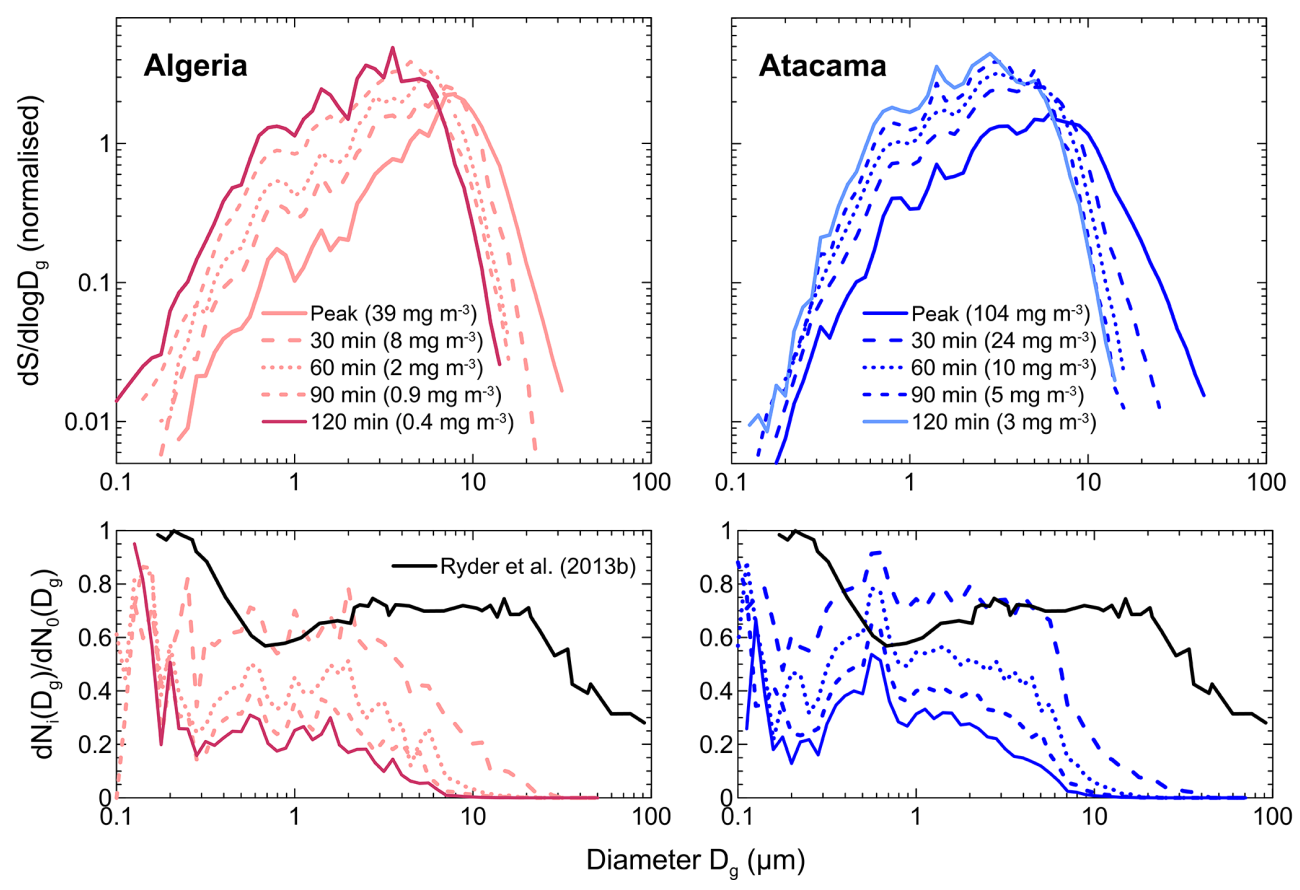

Figure 7. Upper panel: surface size distribution measured at the peak of the dust injection and at 30, 60, 90, and 120 min after injection for the Algeria and Atacama aerosols. The dust mass concentration is also indicated in the plot. Lower panel: fraction of particles remaining airborne in the chamber as a function of time versus particle size calculated as $\mathrm{d} N_{i}\left(D_{\mathrm{g}}\right) / \mathrm{d} N_{0}\left(D_{\mathrm{g}}\right)$, where $\mathrm{d} N_{i}\left(D_{\mathrm{g}}\right)$ is the number of particles measured by size class at time $i$ ( $i$ corresponding to 30,60, 90, and $120 \mathrm{~min}$ after injection) and $\mathrm{d} N_{0}\left(D_{\mathrm{g}}\right)$ represents the size-dependent particle number at the peak of the injection. Values are compared to the estimate of Ryder et al. (2013b) for Saharan dust layers aged 1-2 days after emission.

length range, significant differences are observed when comparing the samples, which in turn are linked to differences in their mineralogical composition.

Figure 8 allows the identification of the spectral features of the minerals presenting the strongest absorption bands, in particular in the $8-12 \mu \mathrm{m}$ atmospheric window (Table 3 ). The most prominent absorption peak is found around $9.6 \mu \mathrm{m}$ for all samples, where clays have their $\mathrm{Si}-\mathrm{O}$ stretch resonance peak. The shape around the peak differs according to the relative proportions of illite and kaolinite in the samples, as is illustrated with the results for the Tunisia, Morocco, Ethiopia, Kuwait, Arizona, Patagonia, Gobi, and Taklimakan samples (richer in illite) compared to the Libya, Algeria, Mauritania, Niger, Bodélé, Saudi Arabia, and Australia samples (richer in kaolinite). Aerosols rich in kaolinite also show a secondary peak at $\sim 10.9 \mu \mathrm{m}$. The spectral signature of quartz at 9.2 and $12.5-12.9 \mu \mathrm{m}$ is ubiquitous, with a stronger contribution in the Bodélé, Niger, Patagonia, and Australia samples. Aerosols rich in calcite, such as the Tunisia, Morocco, Saudi Arabia, Taklimakan, Arizona, Atacama, and Namib-1 samples show absorption bands at $\sim 7$ and $11.4 \mu \mathrm{m}$. Conversely, these are not present in the other samples and in particular in none of the samples from the Sahel. Finally, the contribution of feldspars (albite) at $8.7 \mu \mathrm{m}$ is clearly detected only for the Namib-1 sample.
Table 3. Position of LW absorption band peaks $(6-15 \mu \mathrm{m})$ for the main minerals composing dust. Montmorillonite is taken here as representative for the smectite family. For feldspars literature data are available only for albite.

\begin{tabular}{lrl}
\hline Mineral species & Wavelength $(\mu \mathrm{m})$ & Reference \\
\hline Illite & 9.6 & Querry (1987) \\
Kaolinite & $9.0,9.6,9.9,10.9$ & Glotch et al. (2007) \\
Montmorillonite & $9.0,9.6$ & Glotch et al. (2007) \\
Chlorite & 10.2 & Dorschner et al. (1978) \\
Quartz & $9.2,12.5-12.9$ & Peterson and Weinman (1969) \\
Calcite & $7.0,11.4$ & Long et al. (1993) \\
Gypsum & 8.8 & Long et al. (1993) \\
Albite & $8.7,9.1,9.6$ & Laskina et al. (2012) \\
\hline
\end{tabular}

The intensity of the absorption bands depend strongly on the particle size distribution, in particular on the contribution of the aerosol super-micron fraction, as well as on the total dust mass concentration. These, as discussed in the previous section, are associated with the specific characteristics of each of the soils used and their propensity for dust emission. The highest values of dust absorption that can be seen in Fig. 8 for the $8-12 \mu \mathrm{m}$ spectral region appear for the Bodélé aerosol sample. In this particular sample, the supermicron particles represent $45 \%$ of the total particle number at the peak of the injection, and this sample showed the highest mass concentration in the chamber $\left(310 \mathrm{mg} \mathrm{m}^{-3}\right)$. Con- 

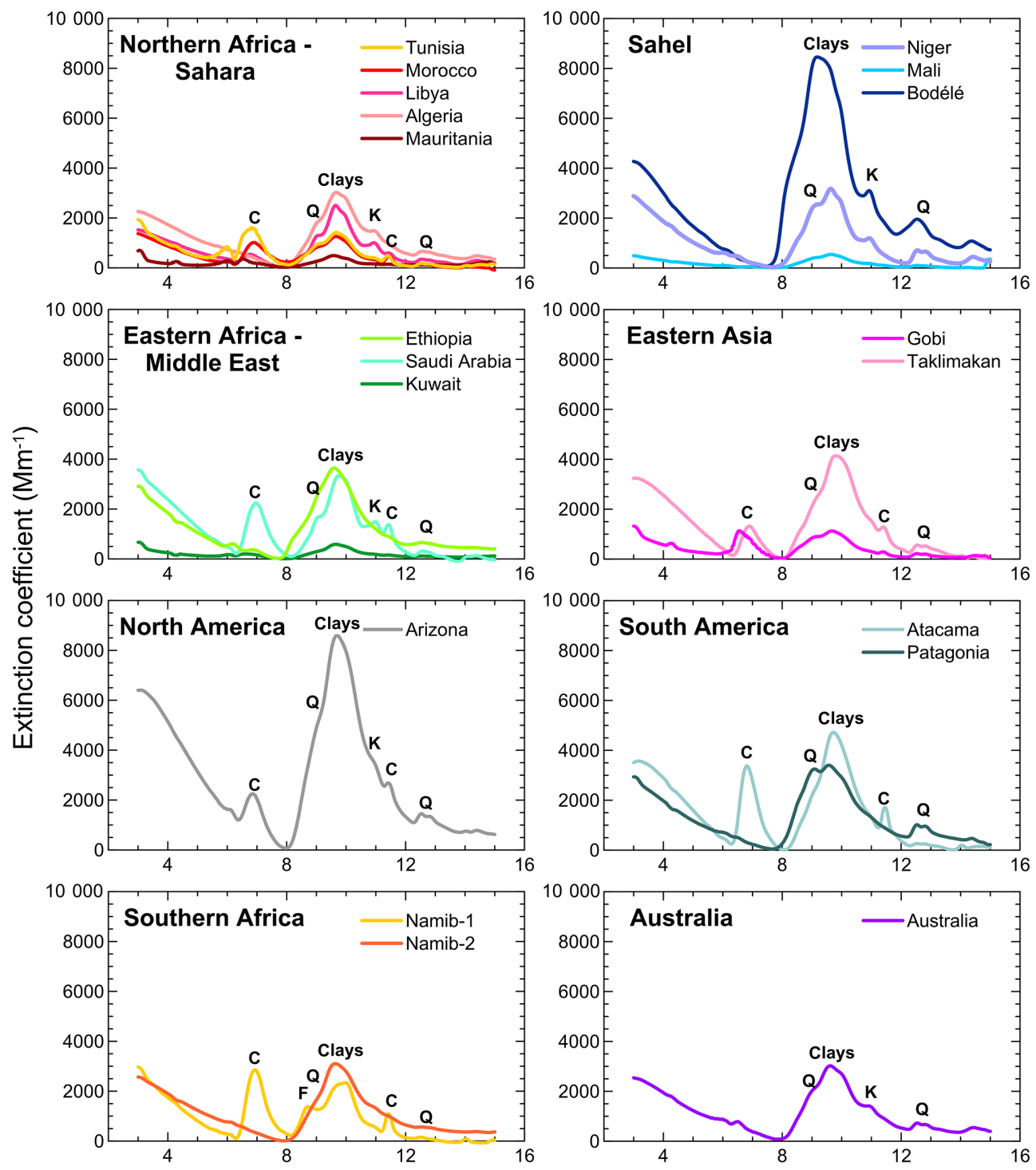

Wavelength $(\mu \mathrm{m})$

Figure 8. Dust extinction coefficient measured in the LW spectral range for the 19 aerosol samples analyzed in this study. Data for each soil refer to the peak of the dust injection in the chamber. Note that the $y$ scale is different for northern Africa-the Sahara compared to the other cases. Main absorption bands by clays at $9.6 \mu \mathrm{m}$, quartz (Q) at 9.2 and $12.5-12.9 \mu \mathrm{m}$, kaolinite $(\mathrm{K})$ at $10.9 \mu \mathrm{m}$, calcite $(\mathrm{C})$ at 7.0 and $11.4 \mu \mathrm{m}$, and feldspars $(\mathrm{F})$ at $8.7 \mu \mathrm{m}$ are also indicated in the spectra.

versely, the lowest absorption is measured for the aerosols from Mauritania, Mali, Kuwait, and Gobi, for which the super-micron particle fraction and the mass concentrations are lower.

The intensity of the spectral extinction rapidly decreases after injection, following the decrease of the super-micron particle number and mass concentration. As an example, Fig. 9 shows the temporal evolution of the measured extinction spectrum for the Algeria and Atacama aerosols. The intensity of the absorption band at $9.6 \mu \mathrm{m}$ is about halved after $30 \mathrm{~min}$ and reduced to $\sim 20-30 \%$ and $<10 \%$ of its initial value after 60 and $90-120 \mathrm{~min}$, respectively. Because of the size-dependence of the mineralogical composition, notably the relative proportions of quartz and calcite with respect to clays (Pye et al., 1987), settling could also modify the spectral shape of the extinction spectrum. This effect was investigated for two example cases, Algeria and Atacama, by looking at the temporal evolution of the ratios of the measured extinction coefficient in some specific mineral absorption bands. Changes would indicate that the time variability of the mineralogical composition is optically significant. For the Algeria case, we have considered the quartz $(12.5 \mu \mathrm{m})$ versus clay $(9.6 \mu \mathrm{m})$ bands, and for the Atacama case the calcite $(\sim 7 \mu \mathrm{m})$ versus clay $(9.6 \mu \mathrm{m})$ bands. 


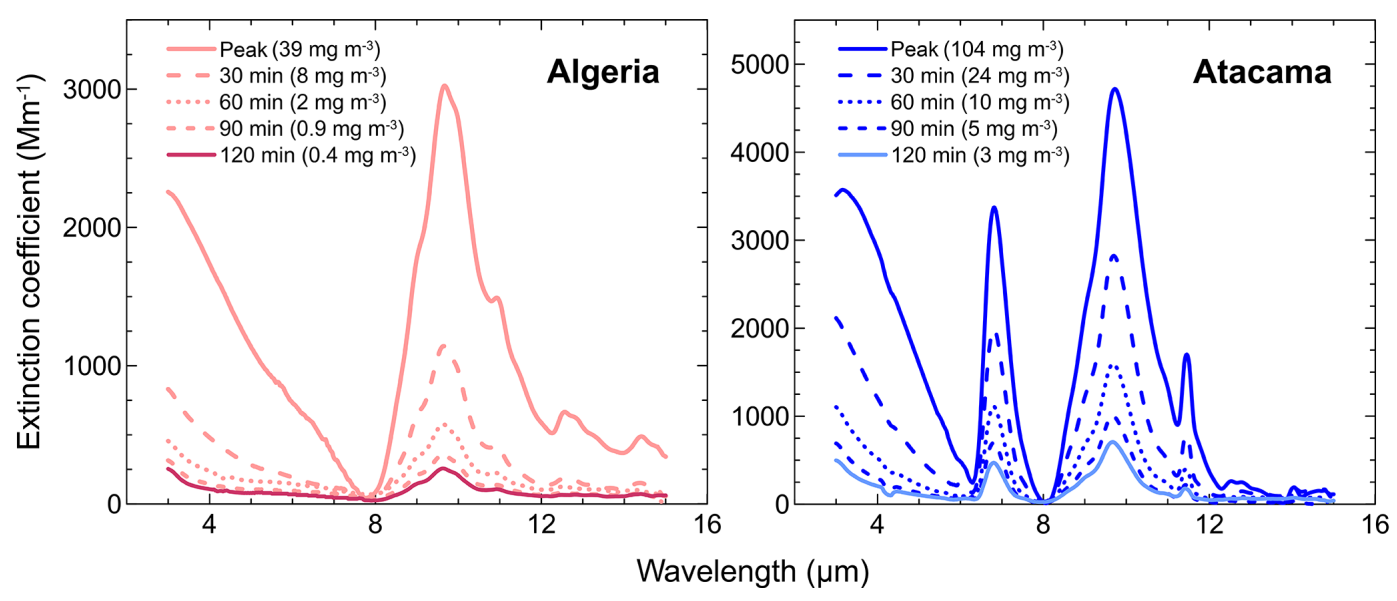

Figure 9. Extinction spectra measured at the peak of the dust injection and at 30,60, 90, and 120 min after injection for the Algeria and Atacama aerosols.

For both cases, the calculated ratios do not change significantly with time, i.e., they agree within error bars: for Algeria, the quartz-to-clay ratio is $0.21 \pm 0.03$ at the peak of the injection and $0.25 \pm 0.04120 \mathrm{~min}$ later; for Atacama, the calcite-to-clay ratio is $0.73 \pm 0.10$ and $0.67 \pm 0.09$ for the same times. Similar results were also obtained for the other samples, with the exception of Saudi Arabia and Morocco, for which we observed an increase of the calcite-to-clay ratio with time. The time invariance of the quartz-to-clays and calcite-to-clays ratios observed for the majority of the analyzed aerosol samples agrees with the observations of the size-dependent dust mineralogical composition obtained by Kandler et al. (2009). These authors showed that in the supermicron diameter range up to $\sim 25 \mu \mathrm{m}$, i.e., in the range where dust is mostly LW-active, the quartz-to-clay and calcite-toclay ratios are approximately constant with size. This would suggest that the loss of particles in this size range should not modify the relative proportions of these minerals, and thus their contributions to LW absorption. Nonetheless, the different behavior observed for Saudi Arabia and Morocco would possibly indicate differences in the size-dependence of the mineralogical composition compared to the other samples.

For each soil, the estimated real $(n)$ and imaginary $(k)$ parts of the complex refractive index are shown in Fig. 10. The reported $n$ and $k$ correspond to the mean of the $10 \mathrm{~min}$ values estimated between the peak of the injection and $120 \mathrm{~min}$ later. This can be done because, for each soil, the time variation of the complex refractive index is moderate. Standard deviations are $<10 \%$ for $n$ and $<20 \%$ for $k$. The data in Fig. 10 are reported by considering as error the absolute uncertainty in $n$ and $k$, previously estimated at $\sim 20 \%$. Figure 10 shows that the dust refractive index widely varies both in magnitude and spectral shape from sample to sample, following the variability of the measured extinction spectra. The values for the real part $n$ span the range 0.84-1.94, while the imaginary part $k$ is between $\sim 0.001$ and 0.92 . The imaginary part, $k$, is observed to vary both from region to region, and also within each region. The differences in $k$ values obtained for different sources within the same region are in most cases larger than the estimated $k$ uncertainties. For specific regions (northern Africa, South America), the variability for $k$ is of a similar order of magnitude to the variability at the global scale. Conversely, the $n$ values mostly agree within error for all soils, both within a region and from one region to another. Exceptions are observed only at wavelengths where strong signatures from specific minerals are found in the $n$ spectrum, as for example at $7 \mu \mathrm{m}$ due to calcite (Saudi Arabia and Gobi samples), or that of quartz at $9.2 \mu \mathrm{m}$ (Patagonia and Australia samples).

\section{Discussion}

\subsection{Predicting the dust refractive index based on its mineralogical composition}

Our results show that the LW refractive index of mineral dust, having different mineralogical compositions, varies considerably. Nevertheless, at wavelengths where the absorption peaks due to different minerals do not overlap, this variability can be predicted from the composition-resolved mass concentrations. These considerations are illustrated in Fig. 11a, where we relate the mean values of the dust $k$ in the calcite, quartz, and clay absorption bands between 7.0 and $11.4 \mu \mathrm{m}$ to the percent mass fraction of these minerals in the dust. Mean $k$ values were calculated as averages over the filter sampling times. For calcite and quartz (resonance peaks at 7.0, 9.2, and $11.4 \mu \mathrm{m}$ ), this relation is almost linear. These two minerals are commonly large in grain size and well crystallized. Their quantification by XRD is certain and they produce a strong and well identified absorption peak in the LW. Nonetheless, there seems to be a lower limit of the percent mass of calcite (around $5 \%$ ) that gives rise to absorption at $7 \mu \mathrm{m}$, and there- 

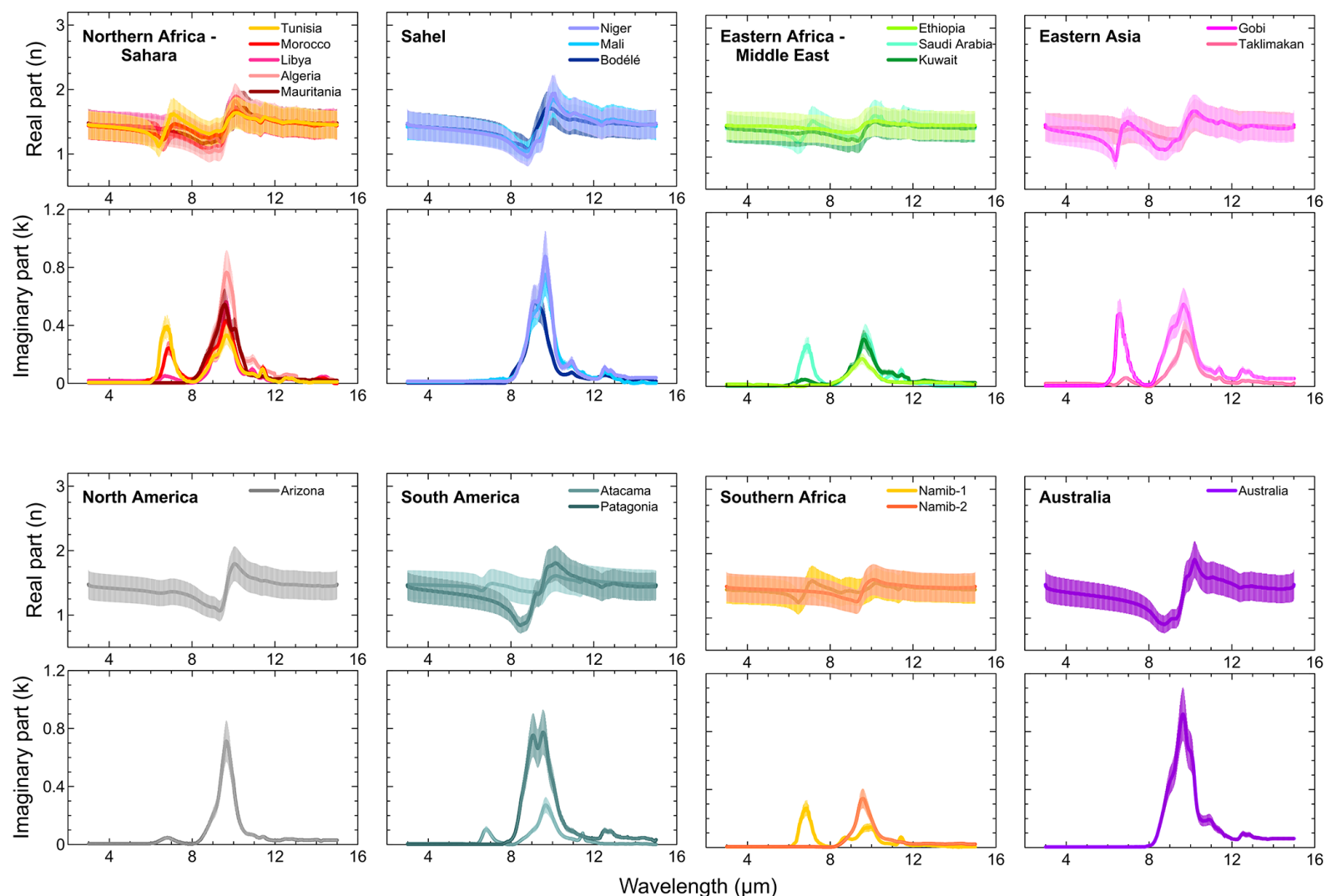

Figure 10. Real $(n)$ and imaginary $(k)$ parts of the dust complex refractive index obtained for the 19 aerosol samples analyzed in this study. Data correspond to the time average of the $10 \mathrm{~min}$ values obtained between the peak of the injection and $120 \mathrm{~min}$ later. The error bar corresponds to the absolute uncertainty in $n$ and $k$, estimated at $\sim \pm 20 \%$.

fore measurable $k$ values. Conversely, at $11.4 \mu \mathrm{m}$, non-zero $k$ values are obtained even in the absence of calcite, due to the interference of the calcite peak and the clay resonance bands. At this wavelength the correlation between $k$ and the calcite mass fraction is also very low.

Poorer or no correlation is found between $k$ and the percent mass fraction in the absorption bands of clays at 9.6 and $10.9 \mu \mathrm{m}$. This different behavior is not unexpected. Clay minerals such as kaolinite, illite, smectite, and chlorite are soil-weathering products containing aluminum and silicon in a $1: 1$ or $1: 2$ ratio (tetrahedral or octahedral structure, respectively). As a consequence, the position of their vibrational peaks is very similar (Dorschner et al., 1978; Querry, 1987; Glotch et al., 2007). In the atmosphere, these minerals undergo aging by gas and water vapor adsorption (Usher et al., 2003; Schuttlefield et al., 2007). As a result of the production conditions in the soils (weathering) and aging in the atmosphere, their physical and chemical conditions (composition, crystallinity, aggregation state) might differ from one soil to another, and from that of mineralogical standards. That is the reason why XRD measurements of clays in natural dust samples might be erroneous, and why we prefer to estimate the clay fraction indirectly. Nonetheless, the in- direct estimate is also prone to error, and depends strongly on an independent estimate of the total mass (which, in the presence of large particles, can be problematic) as well as the correct quantification of the non-clay fraction. This is likely reflected in the large scatter observed in Fig. 11a when trying to relate the $k$ value distribution to the corresponding percent mass of clays. These considerations also affect the speciation of clays, and explain the similar results obtained when separately plotting the spectral $k$ values against the estimated kaolinite or illite masses. The superposition of the resonance bands of these two clays, as well as those of the smectites, which in addition are often poorly crystallized and therefore difficult to detect by XRD, as well as those in the quartz absorption band at $9.2 \mu \mathrm{m}$, suggests that a more formal spectral deconvolution procedure based on single mineral reference spectra is needed to understand the shape and magnitude of the imaginary refractive index in this spectral band.

Similarly to Fig. 11a, Fig. 11b shows the relationship between the mean values of the dust refractive index versus the percent mass fraction of calcite, quartz, and clays at 7.0, 9.2, 9.6, 10.9, and $11.4 \mu \mathrm{m}$ for the real part. The correlation between $n$ and the mineral percent mass fraction is found to be statistically significant only for the calcite band at $7.0 \mu \mathrm{m}$, 
(a)
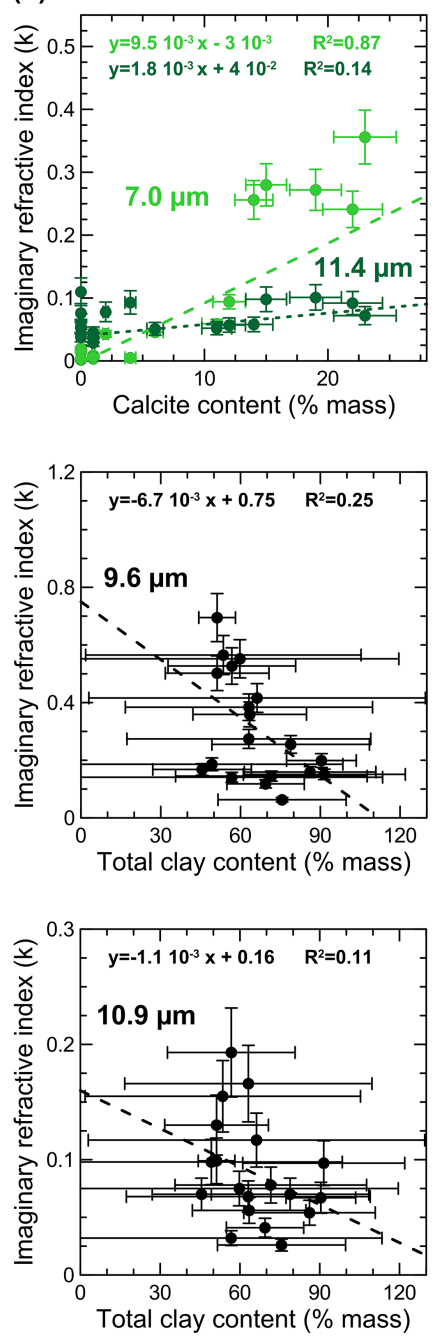

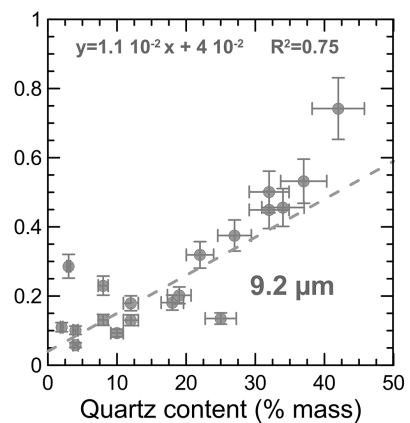

(b)
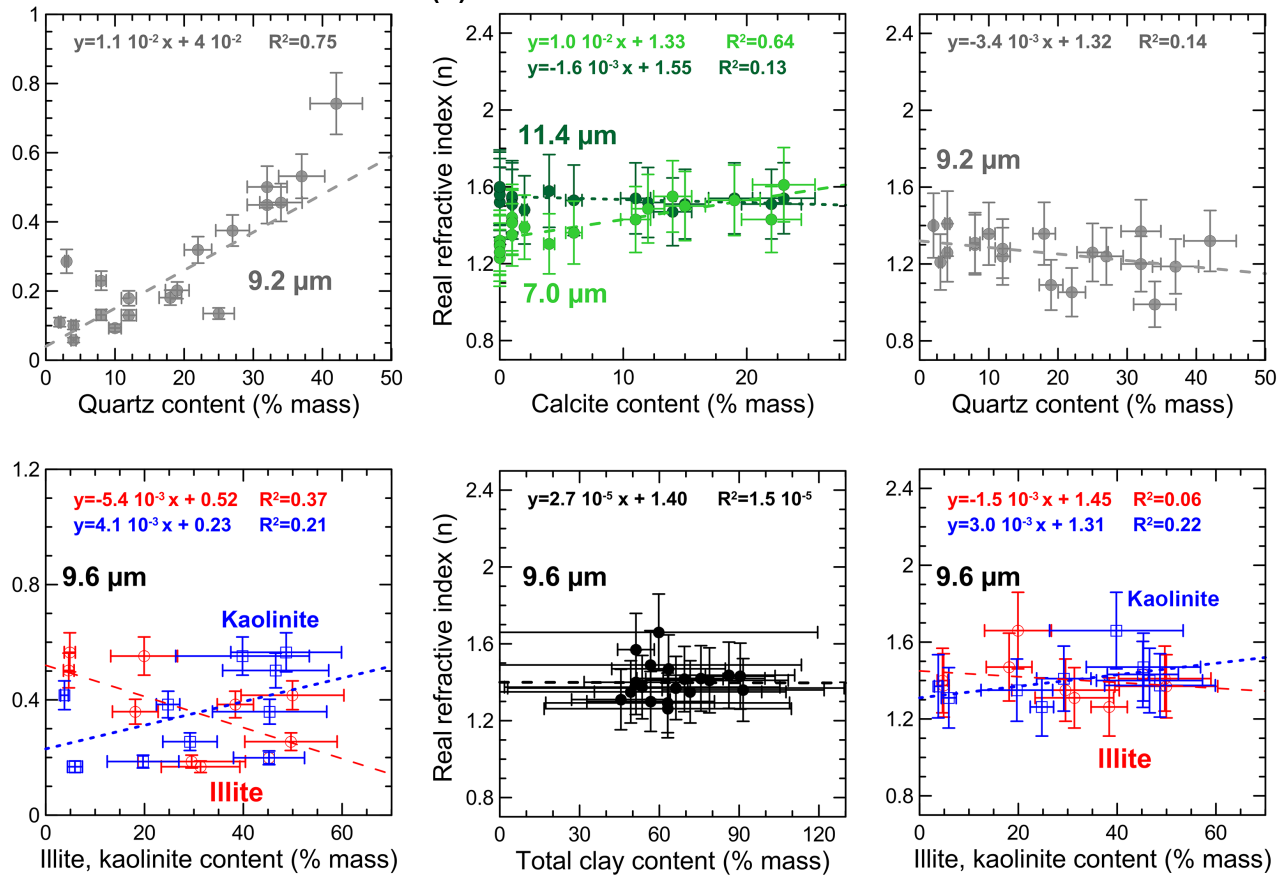
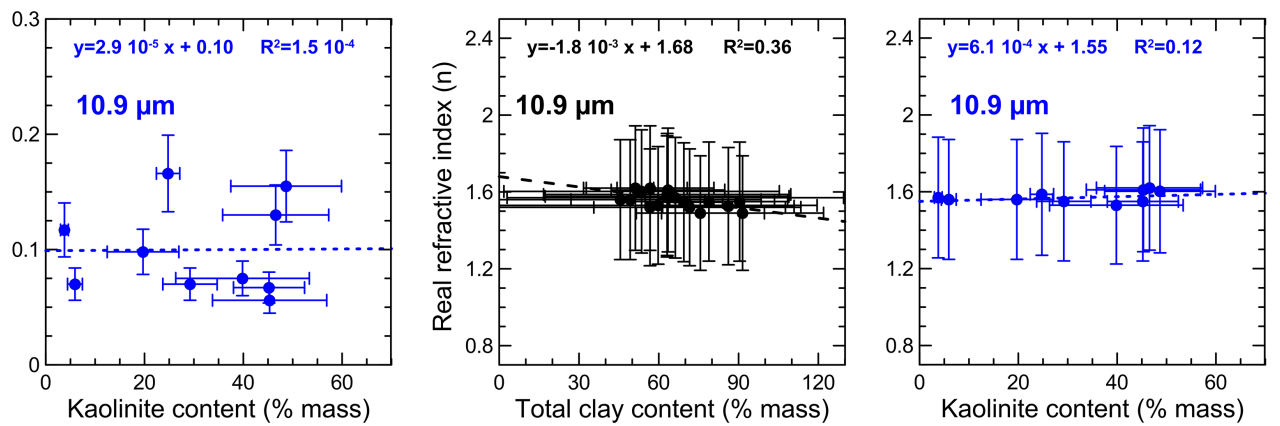

Figure 11. Imaginary part of the complex refractive index $(k)$ versus the mineral content (in $\%$ mass) for the bands of calcite (7.0 and $11.4 \mu \mathrm{m})$, quartz $(9.2 \mu \mathrm{m})$, and clays $(9.6$ and $10.9 \mu \mathrm{m})$. For the band at $9.6 \mu \mathrm{m}$ the plot is drawn separately for total clays, and illite and kaolinite species. The linear fits are also reported for each plot. Linear fits were performed with the FITEXY.PRO Interactive Data Language (IDL) routine taking into account both $x$ and $y$ uncertainties in the data. Same as Fig. 11a for the real part of the complex refractive index $(n)$.

while for all other cases, very poor or no correlation is found. The real refractive index of dust is also almost constant at all bands (with the exception of that at $7.0 \mu \mathrm{m}$ ) regardless of the change in particle composition.

\subsection{Dust complex refractive index versus size distribution during atmospheric transport}

Quantifying the radiative impact of dust depends not only on the ability to provide spatially resolved optical properties, but also on the accurate representation of the possible changes of these properties during transport. In the LW, this effect is amplified by the changes in the size distribution, particularly the loss of coarse particles. Our experiments accurately capture the overall features of the dust size distribution, including the extent and modal position of the coarse-particle mode. However, the depletion rate with time for coarse particles is higher than observed in the atmosphere (e.g., Ryder et al., 2013b). The size distribution after $30 \mathrm{~min}$ still contains a significant, relatively invariant, but not-predictable fraction of coarse particles. This calls for two considerations: (1) the refractive indices obtained at the early stage of the experiments (within $30 \mathrm{~min}$ after the dust injection) are representative of dust at short to medium ranges of transport $(\sim 1-2$ days after emission); (2) the refractive indices after $30 \mathrm{~min}$ of duration are likely to represent long-range transported dust still containing coarse particles in a fraction that will depend on the original soil. In our study, the calculated refractive indices do not change with time in parallel with the observed changes 

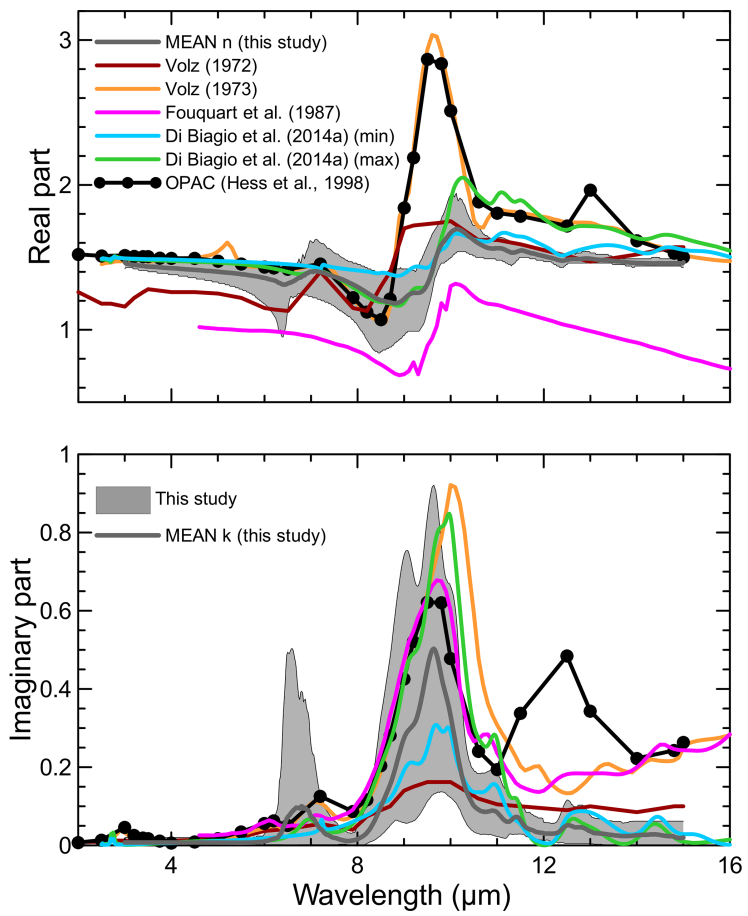

Figure 12. Comparison of results obtained in this study with literature-compiled values of the dust refractive index in the LW. Literature values are taken from Volz (1972) for rainout dust collected in Germany, Volz (1973) for dust collected at Barbados, Fouquart (1987) for Niger sand, Di Biagio et al. (2014a) for dust from Niger and Algeria, and the OPAC database (Hess et al., 1998). The region in gray in the plot indicates the full range of variability obtained in this study, and the dashed line is the mean of $n$ and $k$ obtained for the different aerosol samples. The legend in the top panel identifies the line styles used in the plot for the literature data.

in the size distribution, thus suggesting that a constant value can be assumed close to the source and following transport. Still, further experiments taking into account only the fine fraction of the aerosols will be needed to constrain the sizedependence of the refractive index.

\subsection{Comparison with the literature}

In Fig. 12, we compare our results with estimates of the dust refractive index reported in the literature. We consider data by Volz $(1972,1973)$ for dust collected in Germany and at Barbados, Fouquart et al. (1987) for Niger sand, and Di Biagio et al. (2014a) for dust from Algeria and Niger. We also report data for dust as assumed in the OPAC database (Optical Properties of Aerosols and Clouds; Hess et al., 1998; Koepke et al., 2015). These literature data, in particular those of OPAC and Volz (1973), are the most frequently used references in climate modeling and remote sensing applications. Because of their limited regional span, the literature data clearly cannot do justice to the full range of magnitude and of the spectral variability of the LW complex re- fractive index that is presented in our dataset. In particular, clearly none of the published data represent the contribution of calcite at $\sim 7 \mu \mathrm{m}$. Some of the data (Volz, 1973; Fouquart et al., 1987; OPAC) overestimate $k$ above $11 \mu \mathrm{m}$, where the $12.5-12.9 \mu \mathrm{m}$ quartz absorption band is found. The best correspondence, especially above $10 \mu \mathrm{m}$, is found with Di Biagio et al. (2014a). In the $8-12 \mu \mathrm{m}$ atmospheric window, the agreement with our estimated mean value is moderate, but the range of variability around the mean and its spectral dependence are underrepresented. A shift towards larger wavelengths is also observed for the main clay absorption peak at $\sim 9.6 \mu \mathrm{m}$ for Volz (1973) and Di Biagio et al. (2014a), which is possibly linked to the different method used in these studies to retrieve the complex refractive index (pellet spectroscopy approach) compared to our data. The agreement is even less satisfactory for the real part of the refractive index (upper panel of Fig. 12), which is overestimated in OPAC and Volz (1973) and underestimated in Fouquart et al. (1987). As discussed in Di Biagio et al. (2014a), differences for the real part between the various studies come mostly from the different methods used to estimate the dust refractive index. The methods used in the literature most often do not fulfil the Kramers-Kronig relationship for the $n-k$ couples. The only dataset that fulfils the Kramers-Kronig relationship is Fouquart et al. (1987), but that has the drawback of underestimating $n$ as a consequence of the low value of $n_{\text {vis }}(\sim 1)$ assumed in the retrieval.

On average, the differences between our mean refractive index and the values reported in the literature are large enough to have a significant effect on radiative transfer. For example, at $10 \mu \mathrm{m}$ the absolute difference between our retrieved mean $k$ and the $k$ by OPAC and Volz (1973) is between 0.15 and 0.6. Highwood et al. (2003) have estimated that a change of about 0.3 in $k$ at $10 \mu \mathrm{m}$, which corresponds to half of the difference we have compared to Volz (1973), may result in up to $3 \mathrm{~K}$ change in the modeled sky brightness temperature, the quantity measured by infrared remote sensing. To give a comparison, the same order of brightness temperature difference at $10 \mu \mathrm{m}$ was found between clear sky and dusty conditions for an optical depth of $\sim 1.5$ at $0.55 \mu \mathrm{m}$. This example illustrates the sensitivity of the brightness temperature to the differences in the imaginary part of the refractive index that we find between our data and those in the literature. Another example, of even more relevance for climate applications, is provided by Di Biagio et al. (2014a), who have shown that a 0.3 variation in $k$ is sufficient to induce up to $\sim 15 \%$ of change of the radiative forcing efficiency at $10 \mu \mathrm{m}$ at the TOA.

\section{Conclusions and perspectives}

In this study we have presented a new set of laboratory in situ measurements of the LW extinction spectra and complex refractive indices of mineral dust aerosols from 19 nat- 
ural soils from source regions in northern Africa, the Sahel, Middle East, eastern Asia, North and South America, southern Africa, and Australia. These sources are representative of the heterogeneity of the dust composition at the global scale. Consequently, the envelope of refractive index data obtained in this study can adequately represent the full range of variability for dust as a function of the global variability of its mineralogical composition. These data are expected to be widely applicable for both radiative transfer modeling and remote sensing applications.

The experiments described here were conducted in the realistic and dynamic environment of the $4.2 \mathrm{~m}^{3}$ CESAM. Dust aerosols generated in the chamber are characterized by a realistic size distribution, including both the sub-micron and the super-micron fraction, and they have an atmospherically representative mineralogical composition, including the main LW active minerals, such as quartz, clays, and calcite. The complex refractive index of dust at LW wavelengths is obtained following a rigorous approach that permits the determination of $n-k$ couples that satisfy the Kramers-Kronig relation. Refractive index data from the present study are much more reliable than those provided by DB14, given that a better estimate of $n_{\text {vis }}$ was used in the retrieval algorithm. The average uncertainty in the obtained $n$ and $k$ is $\sim 20 \%$.

The main results from this work can be summarized as follows.

1. The imaginary LW refractive index, $k$, of dust varies strongly both in magnitude and spectral shape as a result of the variability of the particle mineralogy related to the specific emission sources. The value of $k$ is observed to vary both from region to region, as well as within the same region for varying sources. Conversely, for the real part $n$, values are observed to agree within error for the most part of the spectrum for all dust samples. This implies that while a constant $n$ can be taken for dust from different sources, a varying $k$ should be used both at the global and at the regional scale. The available literature data (Volz, 1972, 1973; Fouquart et al., 1987; OPAC, Hess et al., 1998; Koepke et al., 2015) used nowadays in climate models and satellite retrievals do not adequately represent either the magnitude, or the spectral features and the variability of the LW refractive index of mineral dust observed in our dataset. In consequence, we recommend the use of source-specific extinction spectra and/or imaginary refractive indices rather than generic values in models and remote sensing applications.

2. We observe a linear relationship between the magnitude of the imaginary LW refractive index and the mass concentration of specific minerals, i.e., quartz and calcite. This opens the possibility of providing predictive relationships to estimate the LW refractive index of dust at specific bands based on an assumed or predicted mineralogical composition, or conversely, to estimate the dust composition (even partially) from measurements of LW extinction at specific wavebands. This could have important implications for the representation of LW optical properties of dust in climate models, which have started to incorporate the representation of dust mineralogy in their schemes (Scanza et al., 2015; Perlwitz et al., 2015). In addition, the possibility to relate the mass of minerals to the absorption at specific bands, such as for example the calcite band at $\sim 7 \mu \mathrm{m}$, implies that the LW extinction spectra measured from space could be used to distinguish between different dust sources.

3. The spectral shape of the dust extinction spectrum does not seem to change significantly with time as a result of the loss of coarse particles by gravitational settling. This suggests that, despite the dust coarse mode being increasingly depleted, the relative proportions of minerals do not change significantly with time or at least that their changes do not affect the overall optical response of the dust samples. In consequence, the retrieved LW refractive index (real and imaginary) does not change, and therefore can be used to represent short- to mediumrange transport conditions. This finding supports the common practice in global models to treat the dust LW refractive index as static during transport. This also implies that to represent the dust LW refractive index versus mineralogy, models just have to reproduce the dust composition at the source, without the necessity of following its changes during transport, which could be a challenge. This would considerably simplify the representation of dust mineralogy in models.

The unique dataset presented in this study should be particularly useful for improving the dust-climate interactions within regional and global models, and to take into account the geographical variability of the dust LW refractive index, which at present is not represented. This will allow the obtainment of a more realistic representation of the dust LW effect and its radiative forcing upon climate. To date, as shown in Boucher et al. (2013), even the sign of the dust direct effect remains unknown. In this regard, we estimate a lower dust absorption than most of the literature data (see $k$ curves in Fig. 12), and in particular than those of Volz (1973) and OPAC, which are the reference data most frequently used in climate models. The integral of the Volz and OPAC dust refractive indices (imaginary part) between 3 and $15 \mu \mathrm{m}$, for example, is about $15-20 \%$ larger compared to the integral obtained from our max $k$ curve; an up to about 1 order of magnitude overestimate is found when the integral of the Volz and OPAC $k$ over the $3-15 \mu \mathrm{m}$ range is compared to the integral of our min $k$ curve. As a consequence of this, we can conclude that the use of the Volz and OPAC data may introduce a systematic bias in modeling dust radiative effects at LW wavelengths.

The use of the data from the present study also will help to reduce uncertainties in satellite retrievals, thus contributing to improving the remote sensing capability over regions 
affected by dust (Clarisse et al., 2013; Vandenbussche et al., 2013; Capelle et al., 2014; Cuesta et al., 2015).

The work presented in this paper also opens various perspectives: first, as already pointed out, the results of the present study clearly suggest that the LW refractive index of dust varies at the regional scale, as can be observed in Fig. 10 for northern Africa, the Sahel, the Middle East, eastern Asia, South America, and southern Africa. For some particular regions, e.g., northern Africa and South America, the extent of this variability is comparable to the variability obtained at the global scale. The dust samples used in this study were chosen to cover the full heterogeneity of the dust composition at the global scale. However, the available samples do not necessarily explore the possible full variability of the dust composition within each region. This regional variability needs to be characterized further in order to better assess the influence of dust on regional climate.

Second, the possibility of a more formal spectral deconvolution procedure, based on single mineral reference spectra to understand the shape, magnitude, and temporal variability of the refractive index in all different spectral bands, must be investigated. This could strongly help in finding robust relationships linking the dust refractive index to the particle mineralogy.
Third, further experimental efforts by increasing the lifetime and selecting size classes will be needed to better verify the applicability of the obtained refractive indices to longrange transport conditions. Also, the experiments described here were done in conditions when dry deposition is the only aging process. Other aging processes, such as heterogeneous reactions, mixing with other aerosol types, or water uptake, have to be investigated to evaluate their impact on the LW refractive index during transport. For instance, some studies suggest a possible enhancement of dust LW absorption over specific bands if water uptake occurs (Schuttlefield et al., 2007) or if dust mixes with soot (Hansell et al., 2011).

\section{Data availability}

Complex refractive index data are provided in the Supplement. CESAM data are available upon request to the contact authors. 


\section{Appendix A: Control experiment with ammonium sulfate particles}

In order to validate the methodology applied in this study, a control experiment was performed on ammonium sulfate aerosols. Particles were generated from a $0.03 \mathrm{M}$ solution of ammonium sulfate using a constant output atomizer (TSI, model 3075). The aerosol flow passed through a diffusion drier (TSI, model 3062), to be then injected in the CESAM at a flow of $10 \mathrm{~L} \mathrm{~min}^{-1}$ for $10 \mathrm{~min}$. At the peak of the injection the aerosol concentration reached $\sim 160 \mu \mathrm{g} \mathrm{m} \mathrm{m}^{-3}$ and the size distribution was mono-modal and centered at $\sim 0.06 \mu \mathrm{m}$. The LW spectrum of ammonium sulfate measured in CESAM at the peak of the injection is shown in Fig. A1 for the $2-15 \mu \mathrm{m}$ range. Absorption bands attributed to gas-phase water vapor and $\mathrm{CO}_{2}$ present in the chamber during the experiments are indicated in the plot. The 2$15 \mu \mathrm{m}$ spectral region includes three of the four active vibrational modes of ammonium sulfate: $\nu_{3}\left(\mathrm{NH}_{4}^{+}\right)\left(3230 \mathrm{~cm}^{-1}\right.$ or $3.10 \mu \mathrm{m}), v_{4}\left(\mathrm{NH}_{4}^{+}\right)\left(1425 \mathrm{~cm}^{-1}\right.$ or $7.02 \mu \mathrm{m}$; not identified in the plot due to its superposition with the water vapor band), and $\nu_{3}\left(\mathrm{SO}_{2}^{-4}\right)\left(1117 \mathrm{~cm}^{-1}\right.$ or $\left.8.95 \mu \mathrm{m}\right)$. The $\nu_{4}\left(\mathrm{SO}_{2}^{-4}\right)$ is at $620 \mathrm{~cm}^{-1}(16.12 \mu \mathrm{m})$, and thus below the measurement range of the FTIR spectrometer. The retrieval algorithm described in Sect. 3 was applied to estimate the complex refractive index of ammonium sulfate aerosols. Calculations were performed only in the $8-10 \mu \mathrm{m}$ range where the $\nu_{3}\left(\mathrm{SO}_{2}^{-4}\right)$ band is found and where the contamination by water vapor is minimal.
The value of $n_{\text {vis }}$ to use as input to the algorithm was set at 1.55 , based on the analysis of simultaneous SW optical data (not discussed here). The results of the calculations are shown in Fig. A1. The comparison with the optical constants provided by Toon et al. (1976), also shown in Fig. A1, is very satisfactory. A small bias is observed for our retrieved $n$ compared to the values by Toon et al. (1976). This can possibly be linked to the method used in Toon et al. (1976) to retrieve the real part of the refractive index, which is based on the measurement of the normal incident reflectivity of a bulk sample instead of absorption data of aerosol particles, as in our experiments. Overall, the results of the control experiment indicate that the CESAM approach and the proposed retrieval algorithm allow reproduction of the LW spectral signature of the aerosols and estimating accurately their complex refractive index.
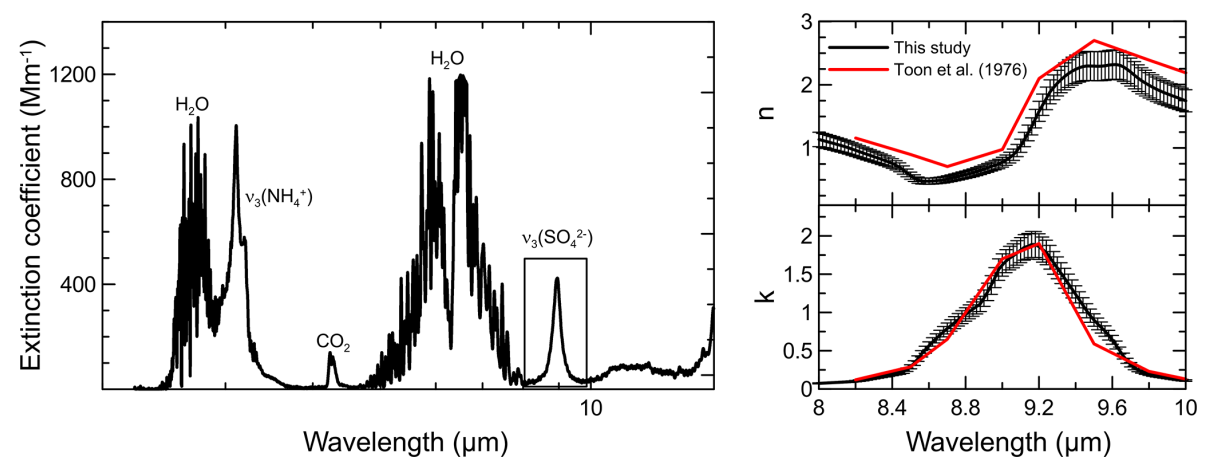

Figure A1. Left panel: long-wave spectrum of ammonium sulfate measured in CESAM in the $2-15 \mu \mathrm{m}$ range. The vibrational modes $v_{3}\left(\mathrm{NH}_{4}^{+}\right)\left(3230 \mathrm{~cm}^{-1}\right.$ or $\left.3.10 \mu \mathrm{m}\right)$ and $v_{3}\left(\mathrm{SO}_{2}^{-4}\right)\left(1117 \mathrm{~cm}^{-1}\right.$ or $\left.8.95 \mu \mathrm{m}\right)$ of ammonium sulfate are identified in the plot. Absorption bands attributed to gas-phase water vapor and $\mathrm{CO}_{2}$ present in the chamber during experiments are also indicated. The rectangle in the plot indicates the spectral region where the retrieval of the complex refractive index was performed. Right panel: real and imaginary parts of the refractive index obtained by optical closure. The results are compared with the ammonium sulfate optical constants from Toon et al. (1976). 


\section{The Supplement related to this article is available online at doi:10.5194/acp-17-1901-2017-supplement.}

Author contributions. Claudia Di Biagio, Paola Formenti, Yves Balkanski, and Jean-François Doussin designed the experiments and discussed the results. Claudia Di Biagio realized the experiments and performed the full data analysis with contributions by Paola Formenti, Lorenzo Caponi, Mathieu Cazaunau, Edouard Pangui, Sandrine Caquineau, and Jean-François Doussin. Sophie Nowak performed the XRD measurements. Meinrat O. Andreae, Konrad Kandler, Thuraya Saeed, Stuart Piketh, David Seibert, and Earle Williams collected the soil samples used for experiments. Emilie Journet participated in the selection of the soil samples for experiments and contributed to the scientific discussion. Claudia Di Biagio, Paola Formenti, and Yves Balkanski wrote the paper with comments from all co-authors.

Competing interests. The authors declare that they have no conflict of interest.

Acknowledgements. This work has received funding from the European Union's Horizon 2020 research and innovation programme through the EUROCHAMP-2020 Infrastructure Activity under grant agreement no. 730997. It was supported by the French national programme LEFE/INSU, by the OSU-EFLUVE (Observatoire des Sciences de l'Univers-Enveloppes Fluides de la Ville à l'Exobiologie) through dedicated research funding, by the CNRS-INSU by supporting CESAM as national facility, and by the project of the TOSCA program of the CNES (Centre National des Etudes Spatiales). Claudia Di Biagio was supported by the CNRS via the Labex L-IPSL, which is funded by the ANR (grant no. ANR-10-LABX-0018). Konrad Kandler received support from the German Science Foundation DFG (KA 2280/2). Field sampling in Saudi Arabia was supported by a grant from King Saud University. The authors strongly thank S. Alfaro, B. Chatenet, M. Kardous, R. Losno, B. Marticorena, J. L. Rajot, and G. Vargas, who participated in the collection of the soil samples from Tunisia, Niger, Atacama, Patagonia, and the Gobi desert used in this study, and S. Chevailler, G. Landrot, and E. Fonda for their contribution in the WD-XRF and XANES analyses. The authors wish to acknowledge J. L. Rajot and two anonymous reviewers for their helpful comments.

Edited by: E. Gerasopoulos

Reviewed by: two anonymous referees

\section{References}

Alfaro, S. C., Lafon, S., Rajot, J. L., Formenti, P., Gaudichet, A., and Maillé, M.: Iron oxides and light absorption by pure desert dust: an experimental study, J. Geophys. Res., 109, D08208, doi:10.1029/2003JD004374, 2004.

Balkanski, Y., Schulz, M., Claquin, T., and Guibert, S.: Reevaluation of Mineral aerosol radiative forcings suggests a better agreement with satellite and AERONET data, Atmos. Chem. Phys., 7, 81-95, doi:10.5194/acp-7-81-2007, 2007.

Bohren, C. E. and Huffman, D. R.: Absorption and Scattering of Light by Small Particles, Wiley, New York, 1983.

Boucher, O., Randall, D., Artaxo, P., Bretherton, C., Feingold, G., Forster, P., Kerminen, V.-M., Kondo, Y., Liao, H., Lohmann, U., Rasch, P., Satheesh, S. K., Sherwood, S., Stevens, B., and Zhang, X. Y.: Clouds and Aerosols, Climate Change 2013: The Physical Science Basis, Contribution of Working Group I to the Fifth Assessment Report of the Intergovernmental Panel on Climate Change, edited by: Stocker, T. and Qin, D., Cambridge Univ. Press, Cambridge, United Kingdom and New York, NY, USA, 2013.

Capelle, V., Chédin, A., Siméon, M., Tsamalis, C., Pierangelo, C., Pondrom, M., Crevoisier, C., Crepeau, L., and Scott, N. A.: Evaluation of IASI-derived dust aerosol characteristics over the tropical belt, Atmos. Chem. Phys., 14, 9343-9362, doi:10.5194/acp14-9343-2014, 2014.

Caponi, L., Formenti, P., Massabó, D., Di Biagio, C., Cazaunau, M., Pangui, E., Chevaillier, S., Landrot, G., Andreae, M. O., Kandler, K., Piketh, S., Saeed, T., Seibert, D., Williams, E., Balkanski, Y., Prati, P., and Doussin, J.-F.: Spectral- and size-resolved mass absorption efficiency of mineral dust aerosols in the shortwave: a simulation chamber study, Atmos. Chem. Phys. Discuss., doi:10.5194/acp-2017-5, in review, 2017.

Caquineau, S., Magonthier, M. C., Gaudichet, A., and Gomes, L.: An improved procedure for the X-ray diffraction analysis of lowmass atmospheric dust samples, Eur. J. Mineral., 9, 157-166, 1997.

Caquineau, S., Gaudichet, A., Gomes, L., and Legrand, M.: Mineralogy of Saharan dust transported over northwestern tropical Atlantic Ocean in relation to source regions, J. Geophys. Res., 107, 4251, doi:10.1029/2000JD000247, 2002.

Claquin, T., Schulz, M., Balkanski, Y. J., and Boucher, O.: Uncertainties in assessing radiative forcing by mineral dust, Tellus B, 50, 491-505, 1998.

Claquin, T., Schulz, M., and Balkanski, Y. J.: Modeling the mineralogy of atmospheric dust sources, J. Geophys. Res., 104, 22243 22256, 1999.

Clarisse, L., Coheur, P.-F., Prata, F., Hadji-Lazaro, J., Hurtmans, D., and Clerbaux, C.: A unified approach to infrared aerosol remote sensing and type specification, Atmos. Chem. Phys., 13, 2195 2221, doi:10.5194/acp-13-2195-2013, 2013.

Colarco, P. R., Nowottnick, E. P., Randles, C. A., Yi, B., Yang, P., Kim, K.-M., Smith, J. A., and Bardeen, C. G.: Impact of radiatively interactive dust aerosols in the NASA GEOS-5 climate model: Sensitivity to dust particle shape and refractive index, J. Geophys. Res.-Atmos., 119, 753-786, doi:10.1002/2013JD020046, 2014.

Cuesta, J., Eremenko, M., Flamant, C., Dufour, G., Laurent, B., Bergametti, G., Hopfner, M., Orphal, J., and Zhou, D.: Threedimensional distribution of a major desert dust outbreak over 
East Asia in March 2008 derived from IASI satellite observations, J. Geophys. Res., 120, 7099-7127, 2015.

Davies, C. N.: Particle-fluid interaction, J. Aerosol. Sci., 10, 477513, 1979.

Denjean, C., Cassola, F., Mazzino, A., Triquet, S., Chevaillier, S., Grand, N., Bourrianne, T., Momboisse, G., Sellegri, K., Schwarzenbock, A., Freney, E., Mallet, M., and Formenti, P.: Size distribution and optical properties of mineral dust aerosols transported in the western Mediterranean, Atmos. Chem. Phys., 16, 1081-1104, doi:10.5194/acp-16-1081-2016, 2016.

DeSouza-Machado, S. G., Strow, L. L., Hannon, S. E., and Motteler, H. E.: Infrared dust spectral signatures from AIRS, Geophy. Res. Lett., 33, 1-5, 2006.

Di Biagio, C., Boucher, H., Caquineau, S., Chevaillier, S., Cuesta, J., and Formenti, P.: Variability of the infrared complex refractive index of African mineral dust: experimental estimation and implications for radiative transfer and satellite remote sensing, Atmos. Chem. Phys., 14, 11093-11116, doi:10.5194/acp14-11093-2014, 2014a.

Di Biagio, C., Formenti, P., Styler, S. A., Pangui, E., and Doussin, J.-F.: Laboratory chamber measurements of the longwave extinction spectra and complex refractive indices of African and Asian mineral dusts, Geophys. Res. Lett., 41, 6289-6297, doi:10.1002/2014GL060213, 2014b.

Di Biagio, C., Formenti, P., Balkanski, Y., Caponi, L., Cazaunau, M., Pangui, E., Andreae, M. O., Kandler, K., Saeed, T., Piketh, S., Seibert, D., Williams, E., and Doussin, J.-F.: Global scale variability of the mineral dust shortwave refractive index and relationship to iron content, in preparation, 2017.

di Sarra, A., Di Biagio, C., Meloni, D., Monteleone, F., Pace, G., Pugnaghi, S., and Sferlazzo, D.: Shortwave and longwave radiative effects of the intense Saharan dust event of March 25-26, 2010, at Lampedusa (Mediterranean sea), J. Geophys. Res., 116, D23209, doi:10.1029/2011JD016238, 2011.

Dorschner, J., Friedemann, C., and Guertler, J.: Laboratory spectra of phyllosilicates and the interstellar 10-micrometer absorption band, Astron. Nachr., 299, 269-282, 1978.

Dufresne, J.-L., Gautier, C., Ricchiazzi, P., and Fouquart, Y.: Longwave scattering effects of mineral aerosols, J. Atmos. Sci., 59, 1959-1966, 2002.

Flores, J. M., Trainic, M., Borrmann, S., and Rudich, Y.: Effective broadband refractive index retrieval by a white light optical particle counter, Phys. Chem. Chem. Phys., 11, 7943-7950, 2009.

Formenti, P., Rajot, J. L., Desboeufs, K., Saïd, F., Grand, N., Chevaillier, S., and Schmechtig, C.: Airborne observations of mineral dust over western Africa in the summer Monsoon season: spatial and vertical variability of physico-chemical and optical properties, Atmos. Chem. Phys., 11, 6387-6410, doi:10.5194/acp-11-6387-2011, 2011.

Formenti, P., Caquineau, S., Desboeufs, K., Klaver, A., Chevaillier, S., Journet, E., and Rajot, J. L.: Mapping the physicochemical properties of mineral dust in western Africa: mineralogical composition, Atmos. Chem. Phys., 14, 10663-10686, doi:10.5194/acp-14-10663-2014, 2014.

Fouquart, Y., Bonnel, B., Brogniez, G., Buriez, J. C., Smith, L., and Morcrette, J. J.: Observations of Sahara aerosols: Results of ECLATS field experiment, Part II: Broadband radiative characteristics of the aerosols and vertical radiative flux divergence, J. Clim. Appl. Meteorol., 26, 38-52, 1987.
Ginoux, P., Prospero, J. M., Gill, T. E., Hsu, N. C., and Zhao, M.: Global-scale attribution of anthropogenic and natural dust sources and their emission rates based on MODIS Deep Blue aerosol products, Rev. Geophys., 50, RG3005, doi:10.1029/2012RG000388, 2012.

Glotch, T. D., Rossman, G. R., and Aharonson, O.: Mid-infrared $(5-100 \mu \mathrm{m})$ reflectance spectra and optical constants of ten phyllosilicate minerals, Icarus, 192, 604-622, 2007.

Goudie, A. S. and Middleton, N. J.: Saharan dust storms: Nature and consequences, Earth-Sci. Rev., 56, 179-204, 2001.

Goudie A. S. and Middleton, N. J.: Desert dust in the global system. Springer, Berlin, Heidelberg, New York, 2006.

Hansell Jr., R. A., Reid, J. S., Tsay, S. C., Roush, T. L., and Kalashnikova, O. V.: A sensitivity study on the effects of particle chemistry, asphericity and size on the mass extinction efficiency of mineral dust in the earth's atmosphere: from the near to thermal IR, Atmos. Chem. Phys., 11, 1527-1547, doi:10.5194/acp-111527-2011, 2011.

Hess, M., Koepke, P., and Schult, I.: Optical properties of aerosols and clouds: The software package OPAC, B. Am. Meteorol. Soc, 79, 831-844, 1998.

Highwood, E. J., Haywood, J. M., Silverstone, M. D., Newman, S. M., and Taylor, J. P.: Radiative properties and direct effect of Saharan dust measured by the C-130 aircraft during Saharan Dust Experiment (SHADE): 2. Terrestrial spectrum, J. Geophys. Res., 108, 8578, doi:10.1029/2002JD002552, 2003.

Hsu, N. C., Herman, J. R., and Weaver, C. J.: Determination of radiative forcing of Saharan dust using combined TOMS and ERBE data, J. Geophys. Res., 105, 20649-20661, doi:10.1029/2000JD900150, 2000.

Israelevich, P. L., Levin, Z., Joseph, J. H., and Ganor, E.: Desert aerosol transport in the Mediterranean region as inferred from the TOMS aerosol index, J. Geophys. Res., 107, 4572, doi:10.1029/2001JD002011, 2002.

Jeong, G. Y.: Bulk and single-particle mineralogy of Asian dust and a comparison with its source soils, J. Geophys. Res., 113, D02208, doi:10.1029/2007JD008606, 2008.

Journet, E., Balkanski, Y., and Harrison, S. P.: A new data set of soil mineralogy for dust-cycle modeling, Atmos. Chem. Phys., 14, 3801-3816, doi:10.5194/acp-14-3801-2014, 2014.

Kaaden, N., Massling, A., Schladitz, A., Müller, T., Kandler, K., Schütz, L., Weinzierl, B., Petzold, A., Tesche, M., Leinert, S., and Wiedensohler, A.: State of Mixing, Shape Factor, Number Size Distribution, and Hygroscopic Growth of the Saharan Anthropogenic and Mineral Dust Aerosol at Tinfou, Morocco, Tellus B, 61, 51-63, 2009.

Kalashnikova, O. V. and Sokolik, I. N.: Modeling the radiative properties of nonspherical soil-derived mineral aerosols, J. Quant. Spectrosc. Ra., 87, 137-166, 2004.

Kandler, K., Schütz, L., Deutscher, C., Ebert, M., Hofmann, H., Jäckel, S., Jaenicke, R., Knippertz, P., Lieke, K., Massling, A., Petzold, A., Schladitz, A., Weinzierl, B., Wiedensohler, A., Zorn, S., and Weinbruch, S.: Size distribution, mass concentration, chemical and mineralogical composition and derived optical parameters of the boundary layer aerosol at Tinfou, Morocco, during SAMUM 2006, Tellus B, 61, 32-50, doi:10.1111/j.16000889.2008.00385.x, 2009.

Karyampudi, V. M., Palm, S. P., Reagen, J. A., Fang, H., Grant, W. B., Moff, H. R., Moulin, C., Pierce, H. F., Torres, O., Browell, 
E. V., and Melfi, S. H.: Validation of the Saharan dust plume conceptual model using lidar, Meteosat, and ECMWF data, B. Am. Meteorol. Soc., 80, 1045-1075, 1999.

Kim, D., Chin, M., Yu, H., Eck, T. F., Sinyuk, A., Smirnov, A., and Holben, B. N.: Dust optical properties over North Africa and Arabian Peninsula derived from the AERONET dataset, Atmos. Chem. Phys., 11, 10733-10741, doi:10.5194/acp-1110733-2011, 2011.

Klaver, A., Formenti, P., Caquineau, S., Chevaillier, S., Ausset, P., Calzolai, G., Osborne, S., Johnson, B., Harrison, M., and Dubovik, O.: Physico-chemical and optical properties of Sahelian and Saharan mineral dust: in situ measurements during the GERBILS campaign, Q. J. Roy. Meteorol. Soc., 137, 1193-1210, doi:10.1002/qj.889, 2011.

Klüser, L., Martynenko, D., and Holzer-Popp, T.: Thermal infrared remote sensing of mineral dust over land and ocean: a spectral SVD based retrieval approach for IASI, Atmos. Meas. Tech., 4, 757-773, doi:10.5194/amt-4-757-2011, 2011.

Koepke, P., Gasteiger, J., and Hess, M.: Technical Note: Optical properties of desert aerosol with non-spherical mineral particles: data incorporated to OPAC, Atmos. Chem. Phys., 15, 59475956, doi:10.5194/acp-15-5947-2015, 2015.

Laskina, O., Young, M. A., Kleiber, P. D., and Grassian, V. H.: Infrared extinction spectra of mineral dust aerosol: single components and complex mixtures, J. Geophys. Res., 117, D18210, doi:10.1029/2012JD017756, 2012.

Legrand, M., Dubovik, O., Lapyonok, T., and Derimian, Y.: Accounting for particle non-sphericity in modeling of mineral dust radiative properties in the thermal infrared, J. Quant. Spectros. Ra., 149, 219-240, 2014.

Leon, J.-F. and Legrand, M.: Mineral dust sources in the surroundings of the north Indian Ocean, Geophys. Res. Lett., 30, 1309, doi:10.1029/2002GL016690, 2003.

Lepple, F. K. and Brine, C. J.: Organic constituents in eolian dust and surface sediments from northwest Africa, J. Geophys. Res., 81, 1141-1147, 1976.

Liao, H. and Seinfeld, J. H.: Radiative forcing by mineral dust aerosols: sensitivity to key variables, J. Geophys. Res., 103, 31637-31646, doi:10.1029/1998JD200036, 1998.

Long, L. L., Querry, M. R., Bell, R. J., and Alexander, R. W.: Optical properties of calcite and gypsum in crystalline and powdered form in the infrared and far-infrared, Infrared Phys., 34, 191-201, 1993.

Maddy, E. S., DeSouza-Machado, S. G., Nalli, N. R., Barnet, C. D., Strow, L. L., Wolf, W. W., Xie, H., Gambacorta, A., King, T. S., Joseph, E., Morris, V., Hannon, S. E., and Schou, P.: On the effect of dust aerosols on AIRS and IASI operational level 2 products, Geophys. Res. Lett., 39, L10809, doi:10.1029/2012GL052070, 2012.

Maring, H., Savoie, D. L., Izaguirre, M. A., Custals, L., and Reid, J. S.: Mineral dust aerosol size distribution change during atmospheric transport, J. Geophys. Res., 108, 8592, doi:10.1029/2002jd002536, 2003.

Marticorena, B., Chatenet, B., Rajot, J. L., Traoré, S., Coulibaly, M., Diallo, A., Koné, I., Maman, A., NDiaye, T., and Zakou, A.: Temporal variability of mineral dust concentrations over West Africa: analyses of a pluriannual monitoring from the AMMA Sahelian Dust Transect, Atmos. Chem. Phys., 10, 8899-8915, doi:10.5194/acp-10-8899-2010, 2010.
McConnell, C. L., Formenti, P., Highwood, E. J., and Harrison, M. A. J.: Using aircraft measurements to determine the refractive index of Saharan dust during the DODO Experiments, Atmos. Chem. Phys., 10, 3081-3098, doi:10.5194/acp-10-30812010, 2010.

McMurry, P. H. and Rader, D. J.: Aerosol Wall Losses in Electrically Charged Chambers, Aerosol Sci. Technol., 4, 249-268, 1985.

Meloni, D., Junkermann, W., di Sarra, A., Cacciani, M., De Silvestri, L., Di Iorio, T., Estellés, V., Gómez-Amo, J. L., Pace, G., and Sferlazzo, D. M.: Altitude-resolved shortwave and longwave radiative effects of desert dust in the Mediterranean during the GAMARF campaign: Indications of a net daily cooling in the dust layer, J. Geophys. Res.-Atmos., 120, 3386-3407, doi:10.1002/2014JD022312, 2015.

Miller, R. L., Knippertz, P., Pérez García-Pando, C., Perlwitz, J. P., and Tegen, I.: Impact of dust radiative forcing upon climate, in: Mineral Dust: A Key Player in the Earth System, edited by: Knippertz, P. and Stuut, J.-B. W., Springer, 327-357, doi:10.1007/978-94-017-8978-3_13, 2014.

Osada, K., Ura, S., Kagawa, M., Mikami, M., Tanaka, T. Y., Matoba, S., Aoki, K., Shinoda, M., Kurosaki, Y., Hayashi, M., Shimizu, A., and Uematsu, M.: Wet and dry deposition of mineral dust particles in Japan: factors related to temporal variation and spatial distribution, Atmos. Chem. Phys., 14, 1107-1121, doi:10.5194/acp-14-1107-2014, 2014.

Osborne, S. R., Johnson, B. T., Haywood, J. M., Baran, A. J., Harrison, M. A. J., and McConnell, C. L.: Physical and optical properties of mineral dust aerosol during the Dust and Biomass-burning Experiment, J. Geophys. Res., 113, D00C03, doi:10.1029/2007jd009551, 2008.

Otto, S., Bierwirth, E., Weinzierl, B., Kandler, K., Esselborn, M., Tesche, M., Schladitz, A.,Wendisch, M., and Trautmann, T.: Solar radiative effects of a Saharan dust plume observed during SAMUM assuming spheroidal model particles, Tellus B, 61, 270296, doi:10.1111/j.1600-0889.2008.00389.x, 2009.

Perlwitz, J. P., Pérez García-Pando, C., and Miller, R. L.: Predicting the mineral composition of dust aerosols - Part 1: Representing key processes, Atmos. Chem. Phys., 15, 11593-11627, doi:10.5194/acp-15-11593-2015, 2015.

Peterson, J. T. and Weinman, J. A.: Optical properties of quartz dust particles at infrared wavelengths, Geophys. Res. Lett., 74, 69476952, 1969.

Prospero, J. M., Ginoux, P., Torres, O., Nicholson, S. E., and Gill, T. E.: Environmental characterization of global sources of atmospheric soil dust identified with the Nimbus 7 Total Ozone Mapping Spectrometer (TOMS) absorbing aerosol product, Rev. Geophys., 40, 1002, doi:10.1029/2000RG000095, 2002.

Pye, K.: Aeolian Dust and Dust Deposits, Academic Press, London, 334 pp., 1987.

Querry, M.: Optical Constants of Minerals and Other Materials from the Millimeter to the Ultraviolet, Report CRDEC-CR-88009, US Army, Aberdeen, 1987.

Rajot, J. L., Formenti, P., Alfaro, S., Desboeufs, K., Chevaillier, S., Chatenet, B., Gaudichet, A., Journet, E., Marticorena, B., Triquet, S., Maman, A., Mouget, N., and Zakou, A.: AMMA dust experiment: an overview of measurements performed during the dry season special observation period (SOP0) at the Ban- 
izoumbou (Niger) supersite, J. Geophys. Res., 113, D00C14, doi:10.1029/2008jd009906, 2008.

Reid, E. A., Reid, J. S., Meier, M. M., Dunlap, M. R., Cliff, S. S., Broumas, A., Perry, K., and Maring, H.: Characterization of African dust transported to Puerto Rico by individual particle and size segregated bulk analysis, J. Geophys. Res., 108, 8591, doi:10.1029/2002jd002935, 2003.

Reid, J. S., Reid, E. A., Walker, A., Piketh, S., Cliff, S., Mandoos, A. A., Tsay, S.-C., and Eck, T. F.: Dynamics of southwest Asian dust particle size characteristics with implications for global dust research, J. Geophys. Res., 113, D14212, doi:10.1029/2007JD009752, 2008.

Ryder, C. L., Highwood, E. J., Rosenberg, P. D., Trembath, J., Brooke, J. K., Bart, M., Dean, A., Crosier, J., Dorsey, J., Brindley, H., Banks, J., Marsham, J. H., McQuaid, J. B., Sodemann, H., and Washington, R.: Optical properties of Saharan dust aerosol and contribution from the coarse mode as measured during the Fennec 2011 aircraft campaign, Atmos. Chem. Phys., 13, 303325, doi:10.5194/acp-13-303-2013, 2013a.

Ryder, C. L., Highwood, E. J., Lai, T. M., Sodemann, H., and Marsham, J. H: Impact of atmospheric transport on the evolution of microphysical and optical properties of Saharan dust, Geophys. Res. Lett., 40, 2433-2438, doi:10.1002/grl.50482, 2013 b.

Scanza, R. A., Mahowald, N., Ghan, S., Zender, C. S., Kok, J. F., Liu, X., Zhang, Y., and Albani, S.: Modeling dust as component minerals in the Community Atmosphere Model: development of framework and impact on radiative forcing, Atmos. Chem. Phys., 15, 537-561, doi:10.5194/acp-15-537-2015, 2015.

Scheuvens, D., Schütz, L., Kandler, K., Ebert, M., and Weinbruch, S.: Bulk composition of northern African dust and its source sediments - A compilation, Earth-Sci. Rev., 116, 170-194, 2013.

Schuttlefield, J. D., Cox, D., and Grassian, V. H.: An investigation of water uptake on clays minerals using ATR-FTIR spectroscopy coupled with quartz crystal microbalance measurements, J. Geophys. Res., 112, D21303, doi:10.1029/2007JD008973, 2007.

Schütz, L. and Jaenicke, R.: Particle Number and Mass Distributions above $10^{-4} \mathrm{~cm}$ Radius in Sand and Aerosol of the Sahara Desert, J. Appl. Meteorol., 13, 863-870, doi:10.1175/15200450(1974)013<0863:PNAMDA>2.0.CO;2, 1974.

Schütz, L., Jaenicke, R., and Pietrek, H.: Saharan dust transport over the North Atlantic Ocean, Geol. Soc. Am. Spec. Paper, 186, 87100, 10.1130/SPE186-p87, 1981.

Seinfeld, J. H. and Pandis, S. N.: Atmospheric Chemistry and Physics: From Air Pollution to Climate Change, Wiley, New York, 2006.

Sertsu, S. M. and Sánchez, P. A.: Effects of Heating on Some Changes in Soil Properties in Relation to an Ethiopian Land Management Practice, Soil Sci. Soc. Am. J., 42, 940-944, 1978.

Shen, Z. X., Li, X., Cao, J., Caquineau, S., Wang, Y., and Zhang, $X .:$ Characteristics of clay minerals in Asian dust and their environmental significance, China Particuology, 3, 260-264, 2005.

Slingo, A., Ackerman, T. P., Allan, R. P., Kassianov, E. I., McFarlane, S. A., Robinson, G. J., Barnard, J. C., Miller, M. A., Harries, J. E., Russell, J. E., and Dewitte, S.: Observations of the impact of a major Saharan dust storm on the atmospheric radiation balance, Geophys. Res. Lett., 33, L24817, doi:10.1029/2006GL027869, 2006.
Sokolik, I. N., Andronova, A. V., and Jonhson, T. C.: Complex refractive index of atmospheric dust aerosols, Atmos. Environ., 16, 2495-2502, 1993.

Sokolik, I. N. and Toon, O. B.: Direct radiative forcing by anthropogenic airborne mineral aerosols, Nature, 381, 681-683, 1996.

Sokolik, I. N., Toon, O. B., and Bergstrom, R. W.: Modeling the radiative characteristics of airborne mineral aerosols at infrared wavelengths, J. Geophy. Res., 103, 8813-8826, 1998.

Sokolik, I. and Toon, O.: Incorporation of mineralogical composition into models of the radiative properties of mineral aerosol from UV to IR wavelengths, J. Geophys. Res., 104, 9423-9444, 1999.

Sokolik, I. N.: The spectral radiative signature of windblown mineral dust: implications for remote sensing in the thermal IR region, Geophys. Res. Lett., 29, 2154, doi:10.1029/2002GL015910, 2002.

Tegen, I. and Lacis, A. A.: Modeling of particle size distribution and its influence on the radiative properties of mineral dust aerosol, J. Geophys. Res., 101, 19237-19244, doi:10.1029/95JD03610, 1996.

Toon, O. B., Pollack, J. B., and Khare, B. N.: The Optical Constants of Several Atmospheric Aerosol Species: Ammonium Sulfate, Aluminum Oxide, and Sodium Chloride, J. Geophys. Res., 81, 5733-5748, 1976.

Usher, C. R., Michel, A. E., and Grassian, V. H.: Reactions on mineral dust, Chem. Rev., 103, 4883-4939, 2003.

Vandenbussche, S., Kochenova, S., Vandaele, A. C., Kumps, N., and De Mazière, M.: Retrieval of desert dust aerosol vertical profiles from IASI measurements in the TIR atmospheric window, Atmos. Meas. Tech., 6, 2577-2591, doi:10.5194/amt-6-2577-2013, 2013.

Vickery, K. J., Eckardt, F. D., and Bryant, R. G.: A subbasin scale dust plume source frequency inventory for southern Africa, 2005-2008, Geophys. Res. Lett., 40, 5274-5279, doi:10.1002/grl.50968, 2013.

Volz, F. E.: Longwave refractive index of atmospheric aerosol substances, Appl. Opt., 11, 755-759, 1972.

Volz, F. E.: Longwave optical constants of ammonium sulfate, Sahara dust; volcanic pumice and flyash, Appl. Opt., 12, 564-568, 1973.

von der Weiden, S.-L., Drewnick, F., and Borrmann, S.: Particle Loss Calculator - a new software tool for the assessment of the performance of aerosol inlet systems, Atmos. Meas. Tech., 2, 479-494, doi:10.5194/amt-2-479-2009, 2009.

Wang, J., Doussin, J. F., Perrier, S., Perraudin, E., Katrib, Y., Pangui, E., and Picquet-Varrault, B.: Design of a new multi-phase experimental simulation chamber for atmospheric photosmog, aerosol and cloud chemistry research, Atmos. Meas. Tech., 4, 2465-2494, doi:10.5194/amt-4-2465-2011, 2011.

Washington, R., Todd, M. C., Middleton, N., and Goudie, A. S.: Dust-storm source areas determined by the Total Ozone Monitoring Spectrometer and surface observations, Ann. Assoc. Am. Geogr., 93, 297-313, 2003.

Weinzierl, B., Petzold, A., Esselborn, M., Wirth, M., Rasp, K., Kandler, K., Schutz, L., Koepke, P., and Fiebig, M.: Airborne measurements of dust layer properties, particle size distribution and mixing state of Saharan dust during SAMUM 2006, Tellus, 61B, 96-117, doi:10.1111/j.1600-0889.2008.00392.x, 2009. 
White, J. U.: Long optical path of large aperture, J. Opt. Soc. Am., $32,285-288,1942$.
Yang, E.-S., Gupta, P., and Christopher S. A.: Net radiative effect of dust aerosols from satellite measurements over Sahara, Geophys. Res. Lett., 36, L18812, doi:10.1029/2009GL039801, 2009. 